\title{
Microglia are involved in phagocytosis and extracellular digestion during Zika virus encephalitis in young adult immunodeficient mice
}

\author{
William Enlow ${ }^{1 \dagger}$, Maude Bordeleau ${ }^{2,3 \dagger}$, Jocelyne Piret ${ }^{1}$ (1), Fernando González Ibáñez ${ }^{3,4,5}$, Olus Uyar', \\ Marie-Christine Venable1, Nathalie Goyette ${ }^{1}$, Julie Carbonneau' ${ }^{1}$, Marie-Eve Tremblay ${ }^{3,4,5,6,7^{*}}$ (10 and \\ Guy Boivin ${ }^{1 *}$ (D)
}

\begin{abstract}
Background: Zika virus (ZIKV) has been associated with several neurological complications in adult patients.

Methods: We used a mouse model deficient in TRIF and IPS-1 adaptor proteins, which are involved in type I interferon production, to study the role of microglia during brain infection by ZIKV. Young adult mice were infected intravenously with the contemporary ZIKV strain PRVABC59 $\left(1 \times 10^{5} \mathrm{PFUs} / 100 \mu \mathrm{L}\right)$.

Results: Infected mice did not present overt clinical signs of the disease nor body weight loss compared with noninfected animals. However, mice exhibited a viremia and a brain viral load that were maximal $\left(1.3 \times 10^{5}\right.$ genome copies/ $\mathrm{mL}$ and $9.8 \times 10^{7}$ genome copies/g of brain) on days 3 and 7 post-infection (p.i.), respectively. Immunohistochemistry analysis showed that ZIKV antigens were distributed in several regions of the brain, especially the dorsal hippocampus. The number of $\mathrm{Iba} 1^{+} / \mathrm{TMEM} 119^{+}$microglia remained similar in infected versus noninfected mice, but their cell body and arborization areas significantly increased in the stratum radiatum and stratum lacunosum-moleculare layers of the dorsal hippocampus cornu ammoni (CA)1, indicating a reactive state. Ultrastructural analyses also revealed that microglia displayed increased phagocytic activities and extracellular digestion of degraded elements during infection. Mice pharmacologically depleted in microglia with PLX5622 presented a higher brain viral load compared to untreated group $\left(2.8 \times 10^{10}\right.$ versus $8.5 \times 10^{8}$ genome copies/g of brain on day 10 p.i.) as well as an increased number of ZIKV antigens labeled with immunogold in the cytoplasm and endoplasmic reticulum of neurons and astrocytes indicating an enhanced viral replication. Furthermore, endosomes of astrocytes contained nanogold particles together with digested materials, suggesting a compensatory phagocytic activity upon microglial depletion.
\end{abstract}

\footnotetext{
*Correspondence: EveTremblay@uvic.ca; Guy.Boivin@crchudequebec.ulaval.ca

tWilliam Enlow and Maude Bordeleau contributed equally.

${ }^{1}$ Centre de Recherche en Infectiologie, Centre de Recherche du CHU de

Québec-Université Laval, Quebec City, QC, Canada

${ }^{3}$ Neurosciences Axis, Centre de recherche du CHU de Québec-Université

Laval, Quebec City, QC, Canada

Full list of author information is available at the end of the article
} permits use, sharing, adaptation, distribution and reproduction in any medium or format, as long as you give appropriate credit to the original author(s) and the source, provide a link to the Creative Commons licence, and indicate if changes were made. The images or other third party material in this article are included in the article's Creative Commons licence, unless indicated otherwise in a credit line to the material. If material is not included in the article's Creative Commons licence and your intended use is not permitted by statutory regulation or exceeds the permitted use, you will need to obtain permission directly from the copyright holder. To view a copy of this licence, visit http://creativecommons.org/licenses/by/4.0/. The Creative Commons Public Domain Dedication waiver (http://creativeco mmons.org/publicdomain/zero/1.0/) applies to the data made available in this article, unless otherwise stated in a credit line to the data. 
Conclusions: These results indicate that microglia are involved in the control of ZIKV replication and/or its elimination in the brain. After depletion of microglia, the removal of ZIKV-infected cells by phagocytosis could be partly compensated by astrocytes.

Keywords: Zika virus, Encephalitis, Microglia, Astrocytes, Neurons, Phagocytosis, Extracellular digestion, Neuroinflammation

\section{Background}

Zika virus (ZIKV) is an arbovirus belonging to the Flaviviridae family. ZIKV is predominantly spread by Aedes mosquitoes and generally causes a mild and self-limiting febrile illness. However, during the 2013-2017 epidemic, an increasing number of neurological and peripheral nervous system complications related to infection with contemporary strains of ZIKV (Asian lineage) were reported in the South Pacific and Latin America. Epidemiological findings have established a relationship between ZIKV and congenital malformations including microcephaly [1-3]. Furthermore, ZIKV has been associated with Guillain-Barré syndrome as well as with other neurological disorders such as encephalitis, meningitis, encephalomyelitis, myelitis, and seizures in adult patients [4-7]. ZIKV has been shown to infect and replicate in mature neurons in cultured temporal lobe slices of human brains [8]. Viral RNA was reported to persist for up to 42 days in the cerebrospinal fluid (CSF) of young adult rhesus monkeys infected by ZIKV [9]. ZIKV RNA has been detected by RT-PCR in the CSF and brain of adult patients presenting with neurological disorders [10, 11]. Infectious virus was also isolated from CSF samples by culture on permissive cells [12]. Analysis of the CSF revealed lymphocytic pleocytosis, elevated protein levels, and normal glucose, suggesting a neuroinflammatory process [12, 13]. Magnetic resonance imaging showed brain abnormalities similar to those caused by other flaviviruses such as West Nile virus and Japanese encephalitis virus, but no specific findings could be associated with ZIKV [14]. These data suggest that ZIKV can invade the central nervous system (CNS) of adult individuals and promote neuroinflammation. However, the mechanisms underlying neurological disorders induced by ZIKV in the mature brain have not been completely elucidated.

In humans, ZIKV NS5 nonstructural protein induces the proteosomal degradation of interferon (IFN)-regulated transcriptional activator STAT2 and reduces type I IFN production [15]. This mechanism of immune evasion does not occur in mice, such that adult wild-type (WT) mice infected with ZIKV only develop a viremia without brain involvement. This limitation has required the administration of an anti-IFNAR (interferon alpha/beta receptor) antibody to WT mice [16] or the use of mice deficient in IFN receptors to study the pathogenesis of
ZIKV infection in mature brains [17-19]. More recently, the neuropathogenesis of ZIKV was investigated in adult immunocompetent mice infected by intracranial inoculation of the virus $[8,20]$. Viral RNAs are recognized by TLR3 (Toll-like receptor 3) and RIG-I (retinoic acidinducible gene I/)/MDA-5 (melanoma differentiationassociated gene 5) leading to the production of type I IFNs. Our group has previously demonstrated that young adult mice deficient in TRIF (i.e., Toll-interleukin-1 receptor domain-containing adaptor inducing IFN- $\beta$ ) and IPS-1 (i.e., IFN- $\beta$ promoter stimulator 1 ), the adaptor proteins of TLR3 and RIG-I/MDA-5, respectively, neither exhibited clinical signs of the disease nor mortality, when infected by the intravenous route with the contemporary ZIKV strain PRVABC59 [21]. Interestingly, these mice exhibited increased and sustained viral RNA loads in the serum, spleen, eyes, and brain compared with their WT counterparts. Although our TRIF ${ }^{-1-}$ xIPS-1 ${ }^{-1-}$ mice were deficient for the production of type I IFNs, these animals did not develop severe infection compared with IFNAR ${ }^{-1-}$ mice after ZIKV challenge [20]. Thus, TRIF $^{-1-}$ xIPS $-1^{-1-}$ mice are a convenient model to study the pathogenesis of brain infection with a contemporary strain of ZIKV.

Microglia play an important role in neural development, functioning, and plasticity in the normal brain [22, 23]. Microglia also exert a key role in the surveillance and maintenance of tissue integrity through their dynamic ramifications, and they actively maintain homeostasis in the brain [24-26]. In cases of injury or invasion of pathogens in the CNS, microglia are the first line of defense and constitute the major phagocytic cells [27-29]. Following ZIKV infection in embryonic or young adult mouse models, microglia displayed morphological and functional changes including cell body enlargement, ramification remodeling, and increased phagocytic activities $[16,30,31]$. A recent study demonstrated that reactive resident microglia and infiltrating peripheral monocytes play a major role in lethal ZIKV encephalitis in immunocompetent mice infected intracranially with an African lineage strain [20].

As resident microglial cells constitute the first line of defense during viral infection of the brain parenchyma, we used our nonlethal young adult TRIF $^{-1-}$ XIPS- $1^{-1-}$ mouse model infected intravenously with the 
contemporary ZIKV strain PRVABC59 to evaluate the physiological function of microglia in the almost complete absence of infiltrating peripheral monocytes. The effects of microglial depletion on brain infection with ZIKV were investigated in this mouse model using PLX5622, an inhibitor of the colony-stimulating factor 1 receptor tyrosine kinase activity required for microglial survival $[32,33]$. Our results show that microglial cells display morphological characteristics of a reactive state during brain infection by ZIKV. Indeed, microglia show larger cell bodies and modified ramification areas. Ultrastructural analysis also revealed that microglia display phagocytic activities and extracellular digestion of degraded elements. Furthermore, we showed that microglia contribute to the control of ZIKV replication and/or its phagocytic elimination from the brain. Their depletion was associated with an increase in the number of ZIKV antigens stained by immunogold, especially in the cytoplasm and endoplasmic reticulum of neurons and astrocytes indicating an enhanced viral replication. Furthermore, the endosomes of astrocytes contained nanogold particles together with digested materials suggesting a compensatory role for these cells in phagocytosis.

\section{Materials and methods}

\section{Animals}

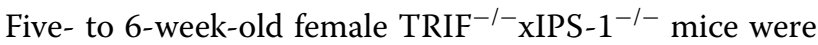
used in this study. $\mathrm{TRIF}^{-1-}$ xIPS-1 ${ }^{-1-}$ mice were generated by Dr. Jean Gosselin (Université Laval, Quebec City, Quebec, Canada) and were maintained on a C57BL/6 background as previously described [21]. Animals were housed three to four per cage and acclimated to standard laboratory conditions.

\section{Infection of mice with ZIKV}

TRIF $^{-1-}$ xIPS-1 ${ }^{-1-}$ mice were infected with a low-passage, contemporary ZIKV strain (Asian lineage) isolated from a human serum specimen from Puerto Rico (PRV$A B C 59)$ in 2015 [34]. An inoculum of $1 \times 10^{5}$ plaqueforming units (PFUs) was administered intravenously in a volume of $100 \mu \mathrm{L}$ of minimum essential medium supplemented with $2 \%$ fetal bovine serum (both from Life Technologies, Burlington, Ontario, Canada). Noninfected mice were used as controls. Some mice ( $n=6$ per group) were monitored for body weight change, clinical signs related to the infection (e.g., reduced mobility, hunched posture, partial or complete paralysis in hind or front limbs), and mortality for 14 days.

\section{Blood collection and preparation of brain homogenates}

On days 0 (noninfected), 3, 7, 10, and 14 post-infection (p.i.), blood was collected from the mandibular vein of a subset of animals ( $n=5-6$ mice per time point) and centrifuged at $1500 \times g$ for $10 \mathrm{~min}$. Viral RNA loads were determined in serum as described below. Mice were then anesthetized by intraperitoneal injection of a mixture of $80 \mathrm{mg} / \mathrm{kg}$ ketamine hydrochloride (Bioniche Animal Health, Belleville, Ontario, Canada) and $10 \mathrm{mg} / \mathrm{kg}$ xylazine (Bimeda, Cambridge, Ontario, Canada) and sacrificed by intracardiac perfusion with cold $0.9 \%$ saline. Brains were harvested, weighed, and homogenized in $1 \mathrm{~mL}$ phosphate-buffered saline (PBS) containing protease (cOmplete) and phosphatase (PhosSTOP) inhibitor cocktails (both from Roche Applied Science, Laval, Quebec, Canada) using the Omni Tissue Homogenizer TH (OMNI International, Ottawa, Ontario, Canada). Brain homogenates were used for the determination of viral genomic RNA and cytokine/chemokine production as described below as well as IFN- $\alpha$ and $-\beta$ mRNA levels (Supplementary methods: Quantification of interferon$\alpha /-\beta$ mRNAs by reverse transcriptase droplet digital PCR).

\section{Determination of viral RNA load by reverse transcriptase droplet digital PCR}

For serum, RNA was extracted from $100 \mu \mathrm{L}$ of sample with the MagNA Pure LC DNA isolation kit (tissue; Roche Molecular System, Laval, Quebec, Canada) and recovered in $50 \mu \mathrm{L}$ of elution buffer. Some samples were adjusted to $100 \mu \mathrm{L}$ with sterile water, and the dilution factor was taken into account. Brain homogenates were centrifuged at $1500 \times g$ for $10 \mathrm{~min}$ at $4{ }^{\circ} \mathrm{C}$. Volumes of supernatants containing $0.01 \mathrm{~g}$ of brain were completed to $80 \mu \mathrm{L}$ with $\mathrm{H}_{2} \mathrm{O}$. RNA was then extracted after addition of $20 \mu \mathrm{L}$ of enzymes using the same isolation kit and protocol as above and recovered in $50 \mu \mathrm{L}$ of elution buffer. The determination of viral genomic RNA in serum and brain homogenates was done as described previously [35]. The droplet digital PCR (ddPCR) workflow and data analyses were performed with the One-Step reverse transcriptase ddPCR Advanced Supermix (Bio-Rad Laboratories, Mississauga, Ontario, Canada) according to the manufacturer's instructions. Briefly, $20 \mu \mathrm{L}$ of reaction mix was used for producing droplets with the QX200 droplet generator (Bio-Rad Laboratories). Droplet-partitioned samples were then transferred to a 96-well plate, sealed and cycled in a C1000 deep well thermocycler (Bio-Rad Laboratories). The cycled plate was then transferred and read in the FAM channel of the QX200 droplet reader (Bio-Rad Laboratories), and data analysis was performed using the QuantaSoft software (Version 1.7.4; Bio-Rad Laboratories).

\section{Cytokine/chemokine production}

Brain homogenates were centrifuged at $10,000 \times g$ for $10 \mathrm{~min}$ at $4{ }^{\circ} \mathrm{C}$. A volume of $50 \mu \mathrm{L}$ of supernatant was 
taken for the determination of cytokine and chemokine levels using a commercial multiplex mouse cytokine magnetic bead-based immunoassay (Bio-Plex Pro Mouse Cytokine 23-plex Assay; Bio-Rad Laboratories) according to the manufacturer's instructions. Mean fluorescence intensity from all the bead combinations was analyzed using of the Bio-Plex system equipped with the Bio-Plex Manager Software v6.0 (Bio-Rad Laboratories).

\section{Tissue processing for light microscopy}

A subset of animals $(n=5-6$ mice per time point) was anesthetized with a mixture of $80 \mathrm{mg} / \mathrm{kg}$ ketamine hydrochloride and $10 \mathrm{mg} / \mathrm{kg}$ xylazine and sacrificed by intracardiac perfusion with PBS followed by $4 \%$ paraformaldehyde (PFA) on days 0 (noninfected), 3, 7, and 10 p.i.. Coronal brain sections. (30- $\mu \mathrm{m}$ thick) were obtained using a sliding microtome (Leica SM2010 R; Leica Biosystems Inc., Wetzlar, Germany) then placed in a cryoprotectant solution (30\% glycerol and 30\% ethylene glycol in PBS) and stored at $-20^{\circ} \mathrm{C}$ until use.

\section{ZIKV distribution within the brain parenchyma by immunoperoxidase staining}

Immunoperoxidase staining of ZIKV envelope antigens was performed as described previously [35]. Freefloating brain sections were quickly rinsed in PBS and washed in PBS $3 \times$ for $10 \mathrm{~min}$. Sections were incubated in $10 \mathrm{mM}$ sodium citrate buffer containing $0.05 \%$ Tween 20 (at pH 6.0) in a water bath at $70{ }^{\circ} \mathrm{C}$ for $40 \mathrm{~min}$, cooled down at room temperature (RT) for $5 \mathrm{~min}$ and washed in PBS $3 \times$ for $10 \mathrm{~min}$. Tissue sections were incubated in Dako dual endogenous block (Agilent Technologies, Santa Clara, CA, USA) for $10 \mathrm{~min}$ and washed in Trisbuffered saline (TBS) containing $0.05 \%$ Triton X-100 (TBS-T). Sections were incubated in blocking buffer (TBS-T containing $1 \%$ bovine serum albumin) for $20 \mathrm{~min}$ and then with a mouse IgG2a recombinant monoclonal antibody to Flavivirus group antigen (D1-4G2-4-15; Absolute Antibody, Oxford, UK) in blocking buffer (1:200) for $30 \mathrm{~min}$ and washed in TBS-T $3 \times$ for $10 \mathrm{~min}$. Sections were incubated with an anti-mouse Dako EnVision + horseradish peroxidase-labeled polymer (Agilent Technologies) for $30 \mathrm{~min}$ then washed in TBS $3 \times$ for $10 \mathrm{~min}$. Sections were recovered with Dako liquid diaminobenzidine $(\mathrm{DAB})+$ substrate chromogen system (Agilent Technologies) and developed for 30 to $60 \mathrm{~s}$. Sections were then washed in TBS $3 \times$ for 10 min and mounted on glass slides. Tissue sections were dehydrated in ascending concentrations of ethanol and cleared in citriSolV solution (ThermoFisher Scientific, Waltham, MA, USA). Sections were rehydrated in descending concentrations of ethanol and counterstained with $0.1 \%$ Cresyl violet acetate (Millipore-Sigma, St. Louis, MO, USA) for $3 \mathrm{~min}$.
Slides were dehydrated again in ascending concentration of ethanol followed by citriSolV, then coverslipped with DPX mounting medium (Electron Microscopy Sciences, Hatfield, PA, USA).

Slides were examined at a magnification of $20 \times$ using a NanoZoomer HT 2.0 slide scanner (Hamamatsu Photonics, Bridgewater, NJ, USA). In this analysis, Bregma -1.35 to -1.55 was selected to include the hippocampus region where the most intense immunostaining was detected [36]. The extent of ZIKV antigen immunostaining was determined by a scoring system (Supplementary Table 1 ). All the analyses were conducted blind to the experimental conditions.

\section{Immunofluorescence labeling of microglia and ZIKV antigens}

Sections containing the dorsal hippocampus (selected Bregma -1.31 to -1.67 ; [36]) were selected for area, distribution, and morphological analyses of microglia on days 0 (noninfected), 7, and 10 p.i. by immunofluorescence microscopy. Tissue sections were quickly rinsed in PBS and washed in PBS $3 \times$ for 10 min to remove the cryoprotectant solution. Antigen retrieval was performed by heating the sections with pre-heated $10 \mathrm{mM}$ sodium citrate buffer containing $0.05 \%$ Tween 20 (at pH 6.0) at $70{ }^{\circ} \mathrm{C}$ for $10 \mathrm{~min}$ and then cooling down with citrate buffer at RT for $5 \mathrm{~min}$. Sections were washed in PBS $5 \times$ for $5 \mathrm{~min}$, incubated in $0.1 \% \mathrm{NaBH}_{4}$ in PBS for $30 \mathrm{~min}$ and washed in PBS $5 \times$ for $5 \mathrm{~min}$. Sections were then incubated in blocking buffer consisting of TBS containing 5\% donkey serum, $0.5 \%$ gelatin (both from Millipore-Sigma) and $0.05 \%$ Triton X-100 at RT for $1 \mathrm{~h}$. The blocking buffer was discarded, and sections were incubated with mouse anti-Flavivirus group antigen (D1-4G2-4-15; Absolute Antibody) (1:400), goat anti-Ibal (ionized calcium-binding adapter 1) (MABN92; Millipore-Sigma) (1:1500), and rabbit antiTMEM119 (transmembrane protein 119) (ab209064; Abcam, Cambridge, UK) (1:300) primary antibodies in blocking buffer at $4{ }^{\circ} \mathrm{C}$ overnight. Sections were put at RT for $15 \mathrm{~min}$ and washed in TBS-T. Sections were incubated with Alexa 488-conjugated donkey anti-mouse, Alexa 568-conjugated donkey anti-goat and Alexa 647-conjugated donkey anti-rabbit secondary antibodies (all from Life Technologies) in blocking buffer (1:300) at RT for $1.5 \mathrm{~h}$ and washed in TBS $5 \times$ for $5 \mathrm{~min}$. Sections were washed in phosphate buffer (PB) $3 \times$ for 5 min, mounted on positively charged glass slides and dried for $2 \mathrm{~h}$. Slides were then treated in 70\% ethanol for $5 \mathrm{~min}$, in Autofluorescence Eliminator Reagent (Millipore-Sigma) for $5 \mathrm{~min}$ and in $70 \%$ ethanol $3 \times$ for $1 \mathrm{~min}$ to eliminate tissue autofluorescence and washed in PB. Slides were coverslipped with Fluoromount-G mounting medium (Southern Biotech, Birmingham, AL, USA) and stored at $4{ }^{\circ} \mathrm{C}$ until use. 
Fluorescence images of the stratum radiatum (st $\mathrm{rad}$ ) and the stratum lacunosum-moleculare (st lac mol) regions of the dorsal hippocampus cornu ammoni (CA)1 were captured at $10 \times$ using a Axio Imager M2 epifluorescence microscope (Zeiss, Oberkochen, Germany) equipped with an AxioCam MRm camera and a $20 \times$ Confocal Quorum WaveFX spinning disk confocal microscope (Quorum Technologies, Guelph, Ontario, Canada) equipped with a Hamamatsu ImageEM camera (Hamamatsu Corporation). Z-stack images acquired by confocal microscope were merged into a single-plane image using the Volocity 4 software (Perkin Elmer, Wellesley, MA, USA).

\section{Microglial population density, distribution, morphology, and co-localization with ZIKV antigens}

All analyses were performed with the ImageJ software (National Institutes of Health, Bethesda, MD, USA) as previously described [37]. Briefly, for microglial density and spacing, the areas examined in the st rad and the st lac mol were delineated using the freehand tool in $10 \times$ pictures (5-6 hippocampi/animal) and measured $\left(\mu \mathrm{m}^{2}\right)$. The center of each individual $\mathrm{Iba}^{+} / \mathrm{TMEM} 19^{+}$ microglial cell body was marked with a dot by the paintbrush tool. Cell number and spatial coordinates were automatically recorded using the analyze particles function to determine the nearest neighbor distance (NND) using the NND plugin. Clusters comprising two or more microglial cells closer than $12 \mu \mathrm{m}$ from one another were counted and averaged by animal. Density (cells number/area) and spacing index (mean $\mathrm{NND}^{2} \times$ density) of microglial cells were calculated for every image and averaged by animal. To analyze morphology, a total of 17-21 microglial cells per animals were examined at $20 \times$. Only complete microglial cells in perfect focus were included in the analysis. For each $\mathrm{Iba} 1^{+} / \mathrm{TMEM}_{119^{+}}$microglia, the soma area was determined by tracing the edge of the cell body with the freehand tool, while the arborization area was evaluated by connecting the most distal extremities of every process with the selection tool. A morphological index was calculated as the ratio of soma area to arborization area in order to evaluate the proportion of cell arborization [37, 38]. The shape descriptors were also determined (i.e., circularity, solidity, aspect ratio, and roundness). Circularity was calculated as $4 \pi x(\mathrm{area} /$ perimeter ${ }^{2}$ ), for which a value of 1.0 represents a perfect circle and around 0.0 an elongated shape. Solidity was calculated by dividing the cell area by the convex cell area meaning that a value close to 0.0 indicates a porous shape and close to 1.0 a convex shape. The aspect ratio was calculated by dividing the major axis by the minor axis of the cell; a value of 1.0 means similar minor and major axes, and higher values indicate that the cell is more elongated.
Finally, roundness was calculated as $4 \times$ area of microglia soma/( $\pi x$ major axis $\left.{ }^{2}\right)$. During morphological analyses, the percentage of $\mathrm{Iba}^{+} / \mathrm{TMEM} 19^{+}$microglial cells colocalizing with ZIKV antigen staining was calculated. In addition, the density of $\mathrm{Iba} 1^{+} / \mathrm{TMEM} 11^{-}$infiltrating myeloid cells (cell number/area) and their ratio over $\mathrm{Iba}^{+}$cells was determined as previously reported [39]. All the analyses were conducted blind to the experimental conditions.

\section{Tissue processing for electron microscopy}

On days 0 (noninfected) and 7 p.i. (which corresponds to the peak of brain viral load), a subset of animals ( $n=4$ mice per time point) was anesthetized with a mixture of $80 \mathrm{mg} / \mathrm{kg}$ ketamine hydrochloride and $10 \mathrm{mg} / \mathrm{kg}$ xylazine. Mice were blood-flushed by intracardiac perfusion with $\sim 15 \mathrm{~mL}$ of ice-cold PBS and then with $\sim 250 \mathrm{~mL}$ of a solution of $4 \%$ PFA $/ 0.2 \%$ glutaraldehyde in $100 \mathrm{mM} \mathrm{PB}(\mathrm{pH}$ 7.4). Brains were post-fixed in 4\% PFA on ice for $2 \mathrm{~h}$ and washed in PBS $3 \times$ for $10 \mathrm{~min}$. Coronal sections of the brain $(50-\mu \mathrm{m}$ thick) were obtained using a vibratome (VT1200 S, Leica) and stored in a cryoprotectant solution at $-20{ }^{\circ} \mathrm{C}$ until use [40]. Sections containing the dorsal hippocampus (selected Bregma-1.55; [36]) were used for immunostaining against ZIKV antigens. Sections were washed in PBS $3 \times$ for $10 \mathrm{~min}$. Sections were quenched with $0.3 \% \mathrm{H}_{2} \mathrm{O}_{2}$ in PBS for $10 \mathrm{~min}$ and washed in PBS $3 \times$ for $10 \mathrm{~min}$. Sections were then permeabilized with $0.1 \% \mathrm{NaBH}_{4}$ in PBS for $30 \mathrm{~min}$ and washed in PBS $3 \times$ for $10 \mathrm{~min}$. Sections were further incubated in blocking solution consisting of $5 \%$ normal goat serum, $1 \%$ bovine serum albumin, $0.05 \%$ Triton X-100 (all from Millipore-Sigma) in TBS at RT for 60 min. Sections were incubated with goat anti-mouse Fc receptor (Jackson ImmunoResearch, West Grove, PA) in TBS (1:12) for $30 \mathrm{~min}$. Sections were then incubated in mouse anti-Flavivirus (Absolute Antibody) primary antibody (1:400) in blocking buffer at $4^{\circ} \mathrm{C}$ overnight and washed in TBS-T $5 \times$ for $5 \mathrm{~min}$. Sections were incubated in goat anti-mouse $1.4 \mathrm{~nm}$ Nanogoldconjugated (Nanoprobes, Yaphank, NY, USA) secondary antibody (1:50) in TBS at $4{ }^{\circ} \mathrm{C}$ overnight and washed in TBS $5 \times$ for $5 \mathrm{~min}$ and then in 3\% sodium acetate solution $2 \times$ for $5 \mathrm{~min}$. Sections were finally revealed by the use of the silver enhancement kit (Nanoprobes) at RT for $1 \mathrm{~min}$. Sections were quickly rinsed in 3\% sodium acetate solution, further rinsed in PB $3 \times$ for $5 \mathrm{~min}$ and washed in PBS $5 \times$ for $3 \mathrm{~min}$. Sections were incubated in a mixture containing equal volumes of $3 \%$ potassium ferrocyanide (BioShop, Burlington, Ontario, Canada) in $0.1 \mathrm{M} \mathrm{PB}$ and $4 \%$ aqueous osmium tetroxide (Electron Microscopy Sciences) at RT for $1 \mathrm{~h}$ and washed in milliQ water $5 \times$ for $3 \mathrm{~min}$. Sections were placed in 
1\% thiocarbohydrazide solution (Electron Microscopy Sciences) at RT for $20 \mathrm{~min}$ and rinsed in milliQ water $5 \times$ for $3 \mathrm{~min}$. Sections were then placed in $2 \%$ aqueous osmium tetroxide at RT for $30 \mathrm{~min}$ and washed in milliQ water $5 \times$ for $3 \mathrm{~min}$. Sections were then dehydrated in ascending concentrations of ethanol $(2 \times 35 \%$, $1 \times 50 \%, 1 \times 70 \%, 1 \times 80 \%, 1 \times 90 \%, 3 \times 100 \%)$ for $5 \mathrm{~min}$ followed by propylene oxide $3 \times$ for $5 \mathrm{~min}$. Sections were transferred in 100\% Durcupan ACM resin (Electron Microscopy Sciences) for $24 \mathrm{~h}$ of infiltration at RT. Tissue sections were then embedded in a thin layer of resin between labeled ACLAR sheets (Electron Microscopy Sciences) and placed in an oven for 3 days of polymerization at $55{ }^{\circ} \mathrm{C}$. After the polymerization, one of the ACLAR sheets was removed, a trapezoid shape of the region of interest was excised from resin-embedded tissue and glued on a resin block to process the embedded tissue for ultramicrotomy. Ultrathin $(\sim 70 \mathrm{~nm})$ sections were cut with an ultramicrotome (Ultracut UC7 ultramicrotome, Leica Biosystems), collected on a silicon nitride chip (Electron Microscopy Sciences) and glued on specimen mounts (Electron Microscopy Sciences). Samples were imaged by array tomography at $5 \mathrm{~nm}(\mathrm{x}$, y) resolution for microglial ultrastructural analysis and $1 \mathrm{~nm}(\mathrm{x}, \mathrm{y})$ resolution for cellular and subcellular localization analysis of nanogold labeling of ZIKV antigens using a Crossbeam 540 (GeminiSEM, Zeiss) field emission scanning electron microscope, with an acceleration voltage of $1.4 \mathrm{kV}$ and current of $1.2 \mathrm{nA}$.

\section{Ultrastructural characterization of microglia}

Ultrastructural analysis of microglia of ZIKV-infected (day 7 p.i.) and noninfected (day 0 ) mice in both layers of the dorsal hippocampus CA1 was performed blind to the experimental conditions using the ImageJ software (st rad: $32-33$ microglia/time point, $6-10$ microglia per animal; st lac mol: 32-36 microglia/time point, 7-10 microglia/animal). Microglia were recognized by their irregular nuclei with a heterogeneous chromatin pattern and a dark irregular cytoplasm, often containing long stretches of endoplasmic reticulum cisternae and lipidic inclusions (i.e. lipofuscin, lysosomes) [41]. Lysosomes, endosomes, lipidic inclusions, as well as altered endoplasmic reticulum, Golgi apparatus, and mitochondria within microglia were first analyzed quantitatively [42]. Lysosomes were identified by their dense heterogeneous contents enclosed by a single membrane [43, 44]. Mature lysosomes were differentiated from immature lysosomes by their contact with fusion endosomes and/or presence of lipofuscin granules (oval structure of finely granular composition with a typical fingerprint-like pattern) [43, 45]. Dilation of the endoplasmic reticulum and/or Golgi apparatus was noted when the distance between the two cisternal membranes was $50 \mathrm{~nm}$ or greater [46, 47]. Mitochondrial abnormalities that were quantified corresponded to elongated (length greater than $1 \mu \mathrm{m}$ ) [42], with hollow appearance, donut-shaped and abnormal [48] mitochondria. Microglial interactions with synaptic elements (i.e., presynaptic axon terminals or postsynaptic dendritic spines), myelinated axons, and degraded myelin of neurons were further identified. Presynaptic axon terminals were differentiated by their synaptic vesicles, while postsynaptic spines were in contact with a presynaptic axon terminal, often with a visible postsynaptic density at their junction [41]. Degraded myelin was recognized by the ballooning, swelling, or distancing of myelin sheaths [41]. Microglial interactions with other brain cell bodies (i.e., neurons and astrocytes) and blood vessels were quantified. Neurons were distinguished by their pale nuclei and pale cytoplasm, often with an apical dendrite and innervation from axon terminals. Astrocytic cells were recognized by their pale nucleus with a thin rim of heterochromatin as well as pale and irregular cytoplasm often containing intermediate filaments [41]. In the vicinity of microglia, the occurrence of degradation activities (e.g., myelin debris, extracellular digestion) was noted. Extracellular digestion or "exophagy" was identified as microglia-associated extracellular space pockets containing degraded elements or debris $[49,50]$.

\section{Effect of microglial depletion with PLX5622 on ZIKV infection of the brain}

TRIF $^{-1}$ xIPS- $1^{-1-}$ mice received PLX5622 (Plexxikon Inc., Berkeley, CA, USA) formulated at a concentration of $1200 \mathrm{mg} / \mathrm{kg}$ in AIN-76A standard rodent diet (Research Diets Inc., New Brunswick, NJ, USA) or AIN-76A control diet ad libitum for 10 days. Blood and brain were collected in a subset of mice $(n=5$ animals per group) the following day. The depletion of microglia was monitored by immunofluorescence staining against Iba1 in brain sections as described above. An evaluation of whether the treatment with PLX5622 could affect the number of total monocytes in the blood was also performed by flow cytometry analyses (Supplementary methods: Determination of blood monocyte levels by flow cytometry).

Groups of mice fed ad libitum with PLX5622 or control chow for 10 days were infected intravenously with ZIKV strain PRVABC59 $\left(1 \times 10^{5}\right.$ PFUs in $\left.100 \mu \mathrm{L}\right)$. Feeding with the respective diets was continued for all the duration of the protocol. Mice ( $n=3$ per group) were monitored for body weight changes, clinical signs associated to the infection and mortality for 10 days as described above. 
Blood and brain of mice ( $n=3$ mice per group and per time point) were collected and processed for the determination of viral RNA load by reverse transcriptase ddPCR on days $0,3,7$, and 10 p.i. as described above. Brain $(n=4$ mice per group and per time point) was also harvested to evaluate the cellular and subcellular distribution of ZIKV antigens labeled with immunogold by scanning electron microscopy analysis on days 0 (noninfected) and 7 p.i. as described above.

\section{Cellular and subcellular distribution of ZIKV antigens labeled with immunogold}

Pictures of all visible nanogold staining of ZIKV antigens in the st rad (36 pictures (7-13 per animal) for untreated and 47 pictures (9-14 per animal) for PLX5622-treated mice) and st lac mol (51 pictures (8-16 per animal) for untreated, and 59 pictures (9-22 per animal) for PLX5622-treated mice) layers of the dorsal hippocampus CA1 on day 7 after ZIKV challenge as well as representative pictures of noninfected animals were acquired. All images were taken within the tissue-resin border, which is the tissue part with the most intense staining. Distribution of nanogold particles was then analyzed qualitatively at the ultrastructural level by an observer blind to the experimental conditions. For each blinded picture, the brain cell type (i.e., neuron, astrocyte, oligodendrocyte, microglia, endothelial cell, pericyte, or other perivascular cells) containing nanogold particles as well as their localization within specific organelles (i.e., cytoplasm, endosome, endoplasmic reticulum, Golgi apparatus, plasma membrane, nuclear membrane, nucleus, and mitochondria membrane) were identified. Specificity of the staining distribution was evaluated by comparing noninfected versus infected mice on day 7 p.i. in both groups.

\section{Statistical analyses}

All statistical analyses were performed using GraphPad Prism software program v8 (GraphPad Software, San Diego, CA, USA). The normal distribution of the data was assessed using a Shapiro-Wilks test and outliers were excluded by Grubb's test, if data were normally distributed. A $P$ value $<0.05$ was considered as statistically significant. Viral load in serum and brain homogenates, cytokine/chemokine levels in brain homogenates, percentage of microglial cells co-localizing with ZIKV antigens, as well as density, distribution, and morphology of microglia were analyzed by a one-way analysis of variance (ANOVA) with Tukey's multiple comparison test. Mean score of viral antigens staining and microglial clustering were analyzed using a nonparametric KruskalWallis test for ordinal variable with Dunn's multiple comparison test. Ultrastructural parameters of microglia were analyzed using a nonparametric Mann-Whitney comparison test.

\section{Results}

ZIKV is associated with a viremia and a brain viral load without causing mortality

Young adult TRIF $^{-1-}$ xIPS- $1^{-1-}$ mice infected intravenously with $1 \times 10^{5}$ PFUs of ZIKV strain PRVABC59 did not exhibit clinical signs of the disease, and all mice survived after infection. The body weight gain of noninfected and ZIKV-infected mice was similar throughout the monitoring period of 14 days (Fig. 1a). However, all mice challenged with ZIKV developed a viremia. The viral RNA load in serum was highest on day 3 (mean of $1.3 \times 10^{5}$ genome copies $/ \mathrm{mL}$ ) and decreased thereafter to become undetectable by day 14 p.i. (Fig. 1b). Viral RNA was further detected in the brain on day 3 and reached a peak value (mean of $9.8 \times 10^{7}$ genome copies/g of brain) on day 7 p.i. (Fig. 1c). The brain viral load decreased thereafter but was still detectable (mean of $2.6 \times 10^{6}$ genome copies/g of brain) on day 14 p.i. Of note, we previously showed that age- and sexmatched WT C57BL/6 mice infected intravenously with the ZIKV strain PRVABC59 exhibited a viremia on day 1 that decreased below the limit of detection of the ddPCR assay on day 3 p.i. [21]. No viral load could be detected in the brain of WT mice after viral challenge. Thus, viral RNA load could be detected in the brain of young adult $\mathrm{TRIF}^{-1-}$ xIPS- $1^{-1-}$ mice from days 3 to 14 p.i. in the absence of clinical signs of infection.

\section{ZIKV increases the levels of selected cytokines and chemokines in the brain}

The levels of cytokines and chemokines in brain homogenates were not significantly affected on day 3 p.i. compared with those measured on day 0 (Table 1). On day 7 p.i., the levels of some cytokines such as IL-1 $\alpha(P<0.05)$, IL-6 $(P<0.05)$, IL-9 $(P<0.01)$, IL-10 $(P<0.05)$, IL-12p70 $(P<0.01)$, and IFN- $\gamma(P<0.05)$ were significantly increased in ZIKV-infected mice compared with noninfected animals (day 0 ), whereas the increase was not significant for the levels of IL-12p40, G-CSF, and TNF- $\alpha$. The levels of chemokines such as CCL2 $(P<0.05)$, CCL3 $(P<0.05)$, CCL4 $(P<0.05)$, CCL11 $(P<0.001)$, and CXCL1 $(P<0.05)$ were also significantly increased on day 7 p.i. in brain homogenates of ZIKV-infected versus noninfected animals. On the other hand, the levels of CCL5 were increased on day 7 compared with those measured on day 0 , but the increase was statistically significant only on day 10 p.i.. The levels of IL-1 $\beta$, IL-2, IL-3, IL-5, IL-13, and IL-17A 

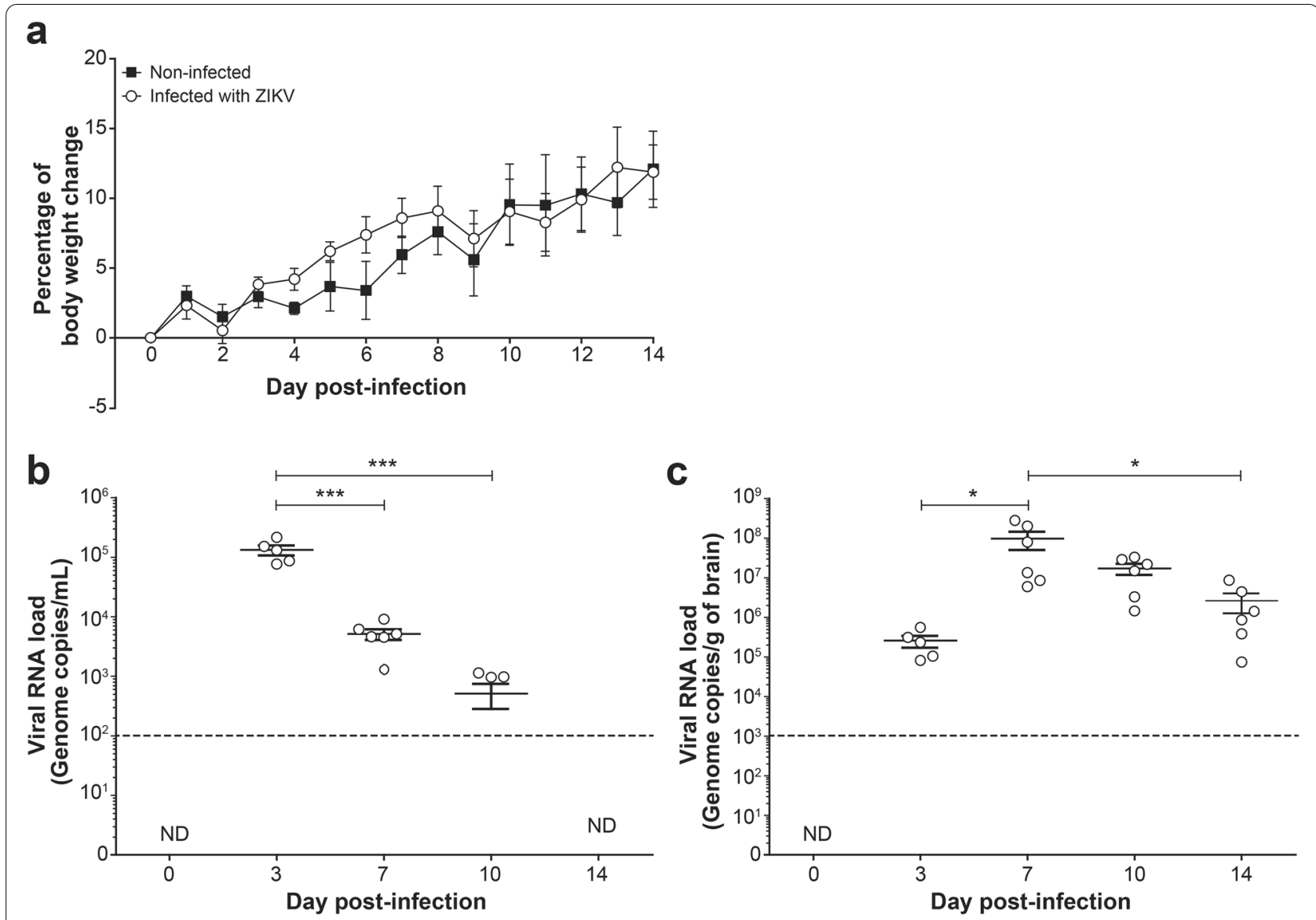

Fig. 1 Body weight change and viral RNA load in serum and brain of young adult mice infected with ZIKV. TRIF ${ }^{-1}$ XIPS-1 ${ }^{-1-}$ mice were infected intravenously with $1 \times 10^{5}$ PFUs of ZIKV strain PRVABC59 in $100 \mu \mathrm{L}$ volume. Noninfected mice were used as controls. a Body weight changes of ZIKV-infected $(O)$ and noninfected $(\mathbf{\square})$ mice. Results represent the mean \pm SEM of 6 mice per group. $\mathbf{b}-\mathbf{c}$ Subsets of mice were sacrificed on days 0 (noninfected), 3, 7, 10, and 14 post-infection and viral RNA load was determined in serum (b) and brain homogenates (c) by reverse transcriptase ddPCR. Results are the mean \pm SEM of 5-6 mice per time point. The dotted lines represent the limit of detection of the reverse transcriptase ddPCR assay. ND, not detected. Statistical analyses were performed using a one-way analysis of variance with Tukey's multiple comparison test. Results that are statistically different between indicated groups are shown as follows: ${ }^{*} P<0.05$; ${ }^{* *} P<0.001$

were not affected after ZIKV challenge. As expected, the levels of IFN- $\alpha$ and $-\beta$ mRNA transcripts in brain homogenates of $\mathrm{TRIF}^{-1-} \mathrm{xIPS}-1^{-/-}$mice determined by reverse transcriptase droplet digital PCR were not affected after ZIKV infection (Supplementary Table 2) suggesting that no signaling pathways other than TLR3 and RIG-I/MDA-5 are involved in type I IFN production. In summary, ZIKV infection induced the production of selected cytokines and chemokines in young adult mouse brains.

\section{ZIKV antigens are more abundant in the dorsal hippocampus}

To examine whether ZIKV infects specific regions of the brain, we performed immunoperoxidase staining of viral envelope antigens. ZIKV antigens were found in several regions of the brain including the ventral and dorsal hippocampi, the thalamus, the hypothalamus, the amygdala, and the cerebral cortex. Figure 2a shows that ZIKV antigens were detected in the dorsal hippocampus, the cortex, and the thalamus as early as on day 3 p.i. Immunostaining increased thereafter and was the most intense on day 10 p.i.. Figure $2 b$ shows that the mean score of ZIKV antigen immunostaining in the dorsal hippocampus increased significantly on days $7(P<0.01)$ and $10(P<0.001)$ p.i. compared with day 0 . The mean score of viral immunostaining was significantly higher in the dorsal hippocampus compared with the amygdala $(P<0.01)$ on day 10 p.i. (Fig. 2c). Thus, ZIKV mainly localized in the dorsal hippocampus among the young adult mouse brain, and its immunostaining was most intense on day 10 p.i. 
Table 1 Cytokine and chemokine levels in the brain of mice infected with Zika virus

\begin{tabular}{|c|c|c|c|c|}
\hline \multirow[t]{2}{*}{ Cytokines/chemokines } & \multicolumn{4}{|c|}{ Amounts (mean \pm SEM) in $\mathrm{pg} / \mathrm{mL}$} \\
\hline & Day 0 & Day 3 post-infection & Day 7 post-infection & Day 10 post-infection \\
\hline IL-1a & $4.28 \pm 0.34$ & $3.93 \pm 0.47$ & $10.44 \pm 2.44^{*}$ & $8.24 \pm 1.13$ \\
\hline $\operatorname{IL}-1 \beta$ & $0.94 \pm 0.02$ & $0.97 \pm 0.03$ & $1.29 \pm 0.20$ & $1.08 \pm 0.06$ \\
\hline $\mathrm{IL}-2$ & $3.20 \pm 0.25$ & $3.20 \pm 0.40$ & $4.36 \pm 0.68$ & $3.65 \pm 0.21$ \\
\hline IL-3 & $0.12 \pm 0.08$ & $0.34 \pm 0.16$ & $0.46 \pm 0.17$ & $0.21 \pm 0.10$ \\
\hline $\mathrm{IL}-5$ & $0.75 \pm 0.12$ & $1.21 \pm 0.20$ & $1.42 \pm 0.31$ & $0.99 \pm 0.13$ \\
\hline IL-6 & $0.95 \pm 0.03$ & $1.20 \pm 0.13$ & $10.65 \pm 4.02^{*}$ & $1.54 \pm 0.26$ \\
\hline IL-9 & $5.55 \pm 0.04$ & $4.77 \pm 0.36$ & $8.50 \pm 0.94^{* *}$ & $4.92 \pm 0.49$ \\
\hline IL-10 & $2.37 \pm 0.98$ & $3.05 \pm 1.44$ & $19.10 \pm 6.40^{*}$ & $13.78 \pm 3.65$ \\
\hline IL-12p40 & $138.91 \pm 8.62$ & $134.58 \pm 14.62$ & $2307.21 \pm 1072.27$ & $2223.27 \pm 637.44$ \\
\hline IL-12p70 & $42.19 \pm 3.09$ & $60.26 \pm 4.92$ & $81.10 \pm 11.42^{* *}$ & $43.06 \pm 4.01$ \\
\hline $\mathrm{IL}-13$ & $109.35 \pm 5.43$ & $127.71 \pm 10.94$ & $124.58 \pm 8.20$ & $108.49 \pm 5.62$ \\
\hline $\mathrm{IL}-17 \mathrm{~A}$ & $2.29 \pm 0.18$ & $2.15 \pm 0.30$ & $2.76 \pm 0.41$ & $2.61 \pm 0.24$ \\
\hline G-CSF & $4.64 \pm 1.55$ & $2.30 \pm 0.82$ & $264.34 \pm 138.48$ & $19.88 \pm 8.10$ \\
\hline $\mathrm{IFN}-\gamma$ & $6.51 \pm 0.76$ & $6.73 \pm 0.75$ & $14.62 \pm 3.37^{*}$ & $8.46 \pm 0.86$ \\
\hline TNF-a & $57.43 \pm 12.71$ & $42.86 \pm 3.50$ & $102.20 \pm 30.40$ & $34.76 \pm 1.79$ \\
\hline $\mathrm{CCL} 2$ & $87.61 \pm 3.78$ & $79.74 \pm 3.85$ & $934.59 \pm 387.08^{*}$ & $284.89 \pm 62.11$ \\
\hline CCL3 & $10.72 \pm 0.30$ & $12.57 \pm 0.32$ & $130.09 \pm 58.52^{*}$ & $59.93 \pm 15.94$ \\
\hline CCL4 & $4.09 \pm 0.42$ & $4.65 \pm 0.36$ & $9.28 \pm 2.00^{*}$ & $7.13 \pm 1.72$ \\
\hline CCL5 & ND & ND & $277.48 \pm 102.87$ & $567.68 \pm 180.00^{* *}$ \\
\hline CCL11 & $44.91 \pm 3.26$ & $44.24 \pm 3.28$ & $180.29 \pm 39.51^{* * *}$ & $82.63 \pm 9.50$ \\
\hline CXCL1 & $15.79 \pm 1.10$ & $12.43 \pm 0.81$ & $51.12 \pm 15.74^{*}$ & $26.66 \pm 3.40$ \\
\hline
\end{tabular}

$N D$, not detected; SEM, standard error of the mean

Results are the mean \pm SEM of 5-6 mice per time point

Statistical analyses were performed using a one-way analysis of variance with Tukey's multiple comparison test. Results that are statistically different compared to day 0 (noninfected mice) are presented as follows: ${ }^{*} P<0.05 ;{ }^{*} P<0.01 ;{ }^{* *} P<0.001$ and are indicated in bold

\section{Microglia co-localize with ZIKV and increase their cell body and arborization areas}

In order to explore a potential interaction between microglia and ZIKV in the brain, we performed triple immunofluorescence staining of viral envelope antigens and of microglial cells with Iba1 and TMEM119 in the st rad and st lac mol layers of the dorsal hippocampus CA1 (see Fig. $2 \mathrm{~d}$ for the anatomical localization). Figure 3a shows the distribution of $\mathrm{Iba}^{+} / \mathrm{TMEM} 19^{+}$microglia and ZIKV antigens in the st rad of noninfected (day 0) and infected (days 7 and 10 p.i.) mice. Figures 3b and 3c show the percentage of $\mathrm{Iba}^{+} / \mathrm{TMEM} 119^{+}$microglia that were found to co-localize with ZIKV antigens on days 7 and 10 p.i. in the st rad and st lac mol, respectively. By day 10 p.i., almost all $\mathrm{Iba1}^{+} / \mathrm{TMEM} 19^{+}$microglia were found to co-localize with ZIKV antigens in both layers of the dorsal hippocampus $(P<0.001$ compared with day 0$)$.

To identify possible functional alterations of microglia during ZIKV infection, we then conducted a detailed analysis of density, distribution, and morphology of $\mathrm{Iba}^{+} / \mathrm{TMEM} 19^{+}$microglia in the st rad and st lac mol layers of the dorsal hippocampus CA1 using fluorescence microscopy. Microglial density, spacing index, and nearest neighbor distance were not affected during ZIKV infection compared with noninfected mice in both layers (Table 2). However, a nonsignificantly increased clustering of microglia, in which neighbor cells lose their territorial organization and become closer to one another, was observed in infected versus noninfected mice (Table 2; Fig. 3d). Despite the increased production of CCL2, the density of $\mathrm{Iba1}^{+} / \mathrm{TMEM} 19^{-}$myeloid cells and their ratio over $\mathrm{Iba1}^{+}$cells were unaffected during ZIKV infection (Table 2). Thus, our mouse model allows the possibility to evaluate the role of microglia during brain infection with ZIKV without contributing effects of infiltrating peripheral monocytes.

Furthermore, changes in microglial morphology were observed for both cell bodies and process arborization. Figure $4 \mathrm{a}$ shows examples of tracing around $\mathrm{Iba}^{+} /$ TMEM119 ${ }^{+}$microglia (using the $\mathrm{Iba}^{+}$channel) on days 0,7 , and 10 p.i. that was used to calculate the areas of cell bodies and arborization processes. On day 10 p.i., microglial cell body area was significantly increased compared with noninfected mice $(P<0.05)$, whereas 


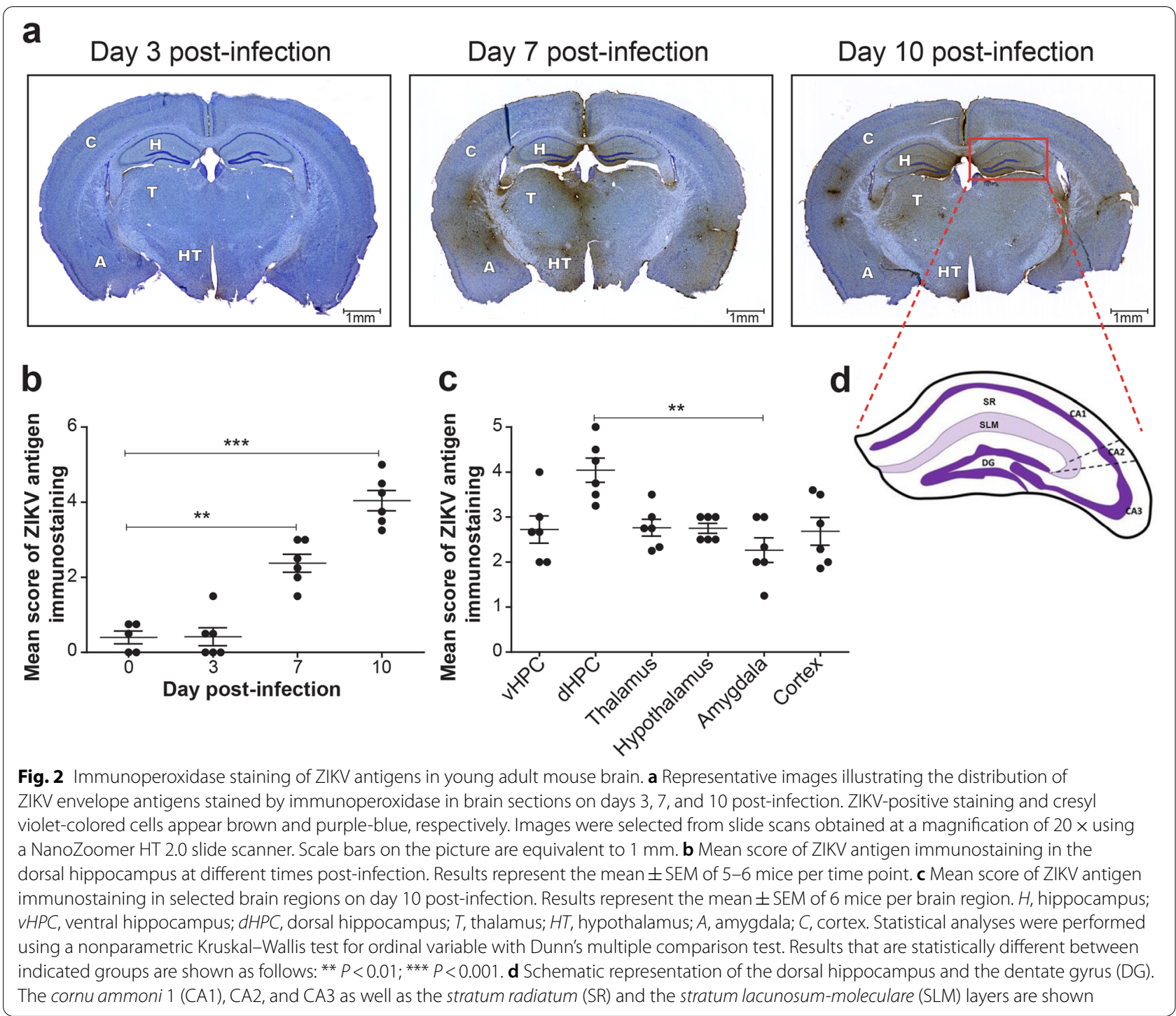

their arborization area was significantly increased compared with day 7 p.i. $(P<0.05)$ in the st rad (Table 3; Fig. 4b) and the st lac mol (Table 3; Fig. 4c). However, the morphological index, calculated as the ratio between the soma and arbor areas, was not affected throughout the infection in both layers of the dorsal hippocampus CA1 (Table 3). No changes in the circularity, solidity, aspect ratio, and roundness of microglial cell body and arborization areas were observed in the st rad. In contrast, the shape descriptor analysis identified a significant decrease in the solidity of microglial arborization areas $(P<0.05)$ in the st lac mol of ZIKVinfected compared with noninfected mice on day 10 p.i.. In the st lac mol, the aspect ratio of microglial arborization areas was also significantly decreased $(P<0.05)$, while their roundness was significantly increased $(P<0.05)$ on day 10 compared to day 7 p.i. suggesting that microglial arborization area, corresponding to their surveyed territory, became rounder between days 7 and 10 p.i.. These changes in microglial cells suggest functional modifications in their interventions with parenchymal elements (such as neurons and other glial cells) and the vasculature in the brain of young adult mice infected with ZIKV.

\section{ZIKV increases microglial lysosome number and induces microglia-associated extracellular digestion}

In order to assess the effect of ZIKV infection on microglial function, we analyzed ultrastructural changes in the organelles of microglial cells and their interactions with their direct environment in the st rad and st lac mol of mice on day 7 p.i. compared with noninfected animals using scanning electron microscopy. More precisely, for each microglia, we quantified the 
a
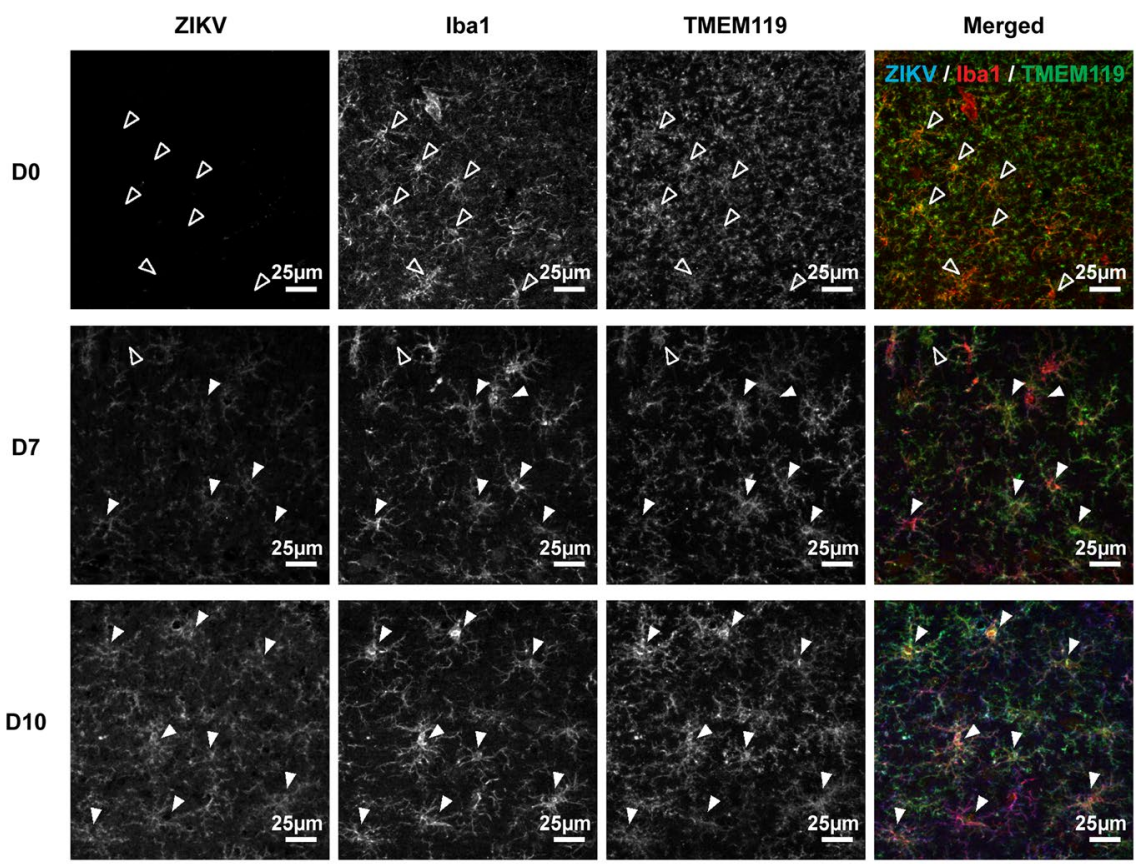

b

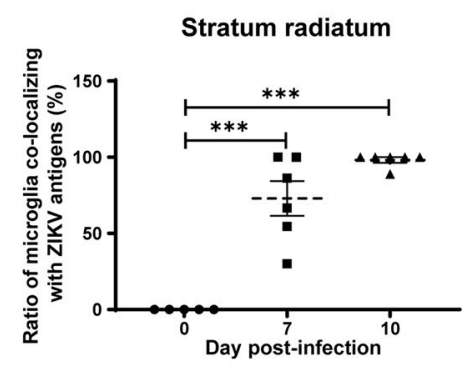

C

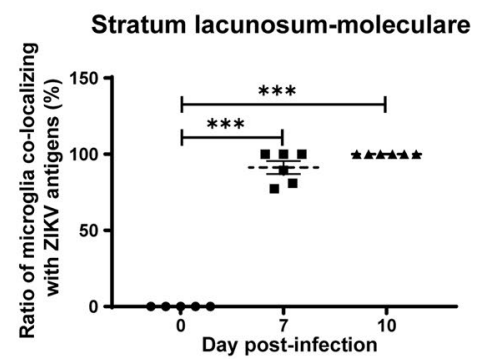

d
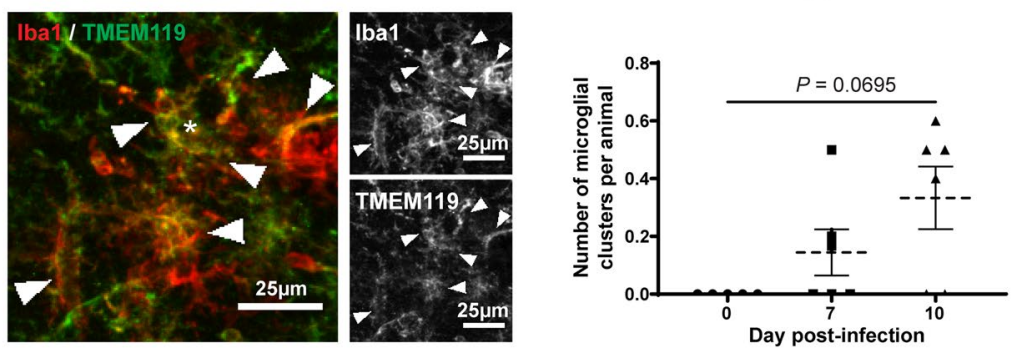

Fig. 3 Co-localization of Iba1+/TMEM119+ microglia and ZIKV antigens in the dorsal hippocampus CA1. a Representative micrographs illustrating the localization of ZIKV antigens and Iba $1^{+} / \mathrm{TMEM} 119^{+}$microglial cells after immunofluorescence labeling in the st rad on days 0 (noninfected), 7, and 10 post-infection. Filled and open arrowheads show microglia co-localizing with ZIKV or not, respectively. Scale bars on the picture are equivalent to $25 \mu \mathrm{m}$. b-c Percentage of Iba ${ }^{+} / \mathrm{TMEM} 119^{+}$microglia co-localizing with ZIKV antigens in the st rad (b) and the st lac mol (c). d Representative micrographs showing a microglial cluster (indicated by an *) and number of microglial clusters per animal during ZIKV infection. Results are the mean \pm SEM of 5-6 hippocampi per animal, for a total of 5-6 mice per time point. Statistical analysis was performed using a one-way ANOVA with Tukey's multiple comparison test. Results that are statistically different between indicated groups are shown as follows: ${ }^{* *} P<0.001$

number of organelles involved in the phagolysosomal pathway (immature and mature lysosomes, endosomes with or without content and lipidic inclusions) and the number of altered organelles that serve as markers of cellular stress (dilated cisternae of endoplasmic reticulum and Golgi apparatus as well as elongated, with hollow appearance, donut-shaped and abnormal mitochondria). We also evaluated the number of contacts of microglial cells with their microenvironment, particularly with neurons (presynaptic axon terminals, 
Table 2 Density and distribution of $\mathrm{Iba} 1^{+} / \mathrm{TMEM}_{1} 19^{+}$microglial cells and infiltrating $\mathrm{Iba} 1^{+} / \mathrm{TMEM} 119^{-}$myeloid cells in both layers of the dorsal hippocampus CA1

\begin{tabular}{|c|c|c|c|c|c|c|}
\hline \multirow[t]{2}{*}{ Parameters } & \multicolumn{3}{|c|}{ Stratum radiatum } & \multicolumn{3}{|c|}{ Stratum lacunosum-moleculare } \\
\hline & $\begin{array}{l}\text { Day } 0 \\
\text { Mean } \pm \text { SEM }\end{array}$ & $\begin{array}{l}\text { Day } 7 \text { p.i. } \\
\text { Mean } \pm \text { SEM }\end{array}$ & $\begin{array}{l}\text { Day } 10 \text { p.i. } \\
\text { Mean } \pm \text { SEM }\end{array}$ & $\begin{array}{l}\text { Day } 0 \\
\text { Mean } \pm \text { SEM }\end{array}$ & $\begin{array}{l}\text { Day } 7 \text { p.i. } \\
\text { Mean } \pm \text { SEM }\end{array}$ & $\begin{array}{l}\text { Day } 10 \text { p.i. } \\
\text { Mean } \pm \text { SEM }\end{array}$ \\
\hline \multicolumn{7}{|l|}{ lba1 ${ }^{+} /$TMEM$_{119}{ }^{+}$microglial cells } \\
\hline Density (cells/mm²) & $211.3 \pm 4.8$ & $206.2 \pm 20.4$ & $218.0 \pm 13.7$ & $232.3 \pm 11.0$ & $220.9 \pm 26.3$ & $275.5 \pm 23.8$ \\
\hline Spacing index (a.u.) & $0.474 \pm 0.007$ & $0.453 \pm 0.013$ & $0.480 \pm 0.018$ & $0.484 \pm 0.016$ & $0.477 \pm 0.014$ & $0.497 \pm 0.010$ \\
\hline $\mathrm{NND}(\mu \mathrm{m})$ & $47.75 \pm 0.66$ & $48.14 \pm 1.94$ & $48.00 \pm 1.49$ & $45.80 \pm 2.08$ & $47.79 \pm 3.04$ & $43.97 \pm 1.62$ \\
\hline Number of clusters per animal & $0.000 \pm 0.000$ & $0.150 \pm 0.081$ & $0.333 \pm 0.109$ & $0.000 \pm 0.000$ & $0.150 \pm 0.081$ & $0.333 \pm 0.109$ \\
\hline \multicolumn{7}{|c|}{ 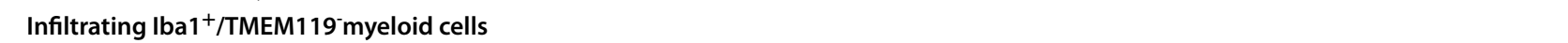 } \\
\hline Density (cells/mm²) & $0.6393 \pm 0.5245$ & $0.1873 \pm 0.1186$ & $1.030 \pm 0.664$ & $3.510 \pm 1.469$ & $2.454 \pm 0.786$ & $4.843 \pm 1.808$ \\
\hline Ratio over Iba ${ }^{+}$cells (\%) & $0.2817 \pm 0.2086$ & $0.0940 \pm 0.0604$ & $0.4300 \pm 0.2764$ & $1.288 \pm 0.510$ & $1.102 \pm 0.330$ & $1.672 \pm 0.458$ \\
\hline
\end{tabular}

a.u., arbitrary unit; NND, nearest neighbor distance; p.i., post-infection; SEM, standard error of the mean

Results are the mean \pm SEM of 5-6 hippocampi per animal for a total of 5-6 mice per time point

Statistical analyses were performed using a one-way analysis of variance with Tukey's multiple comparisons test

postsynaptic dendritic spines), myelin (myelinated axons and degraded myelin), neuronal cell bodies, astrocytic cell bodies, and blood vessels. In the vicinity of microglia, we examined the presence of myelin debris, extracellular space pockets containing degraded elements or debris indicative of extracellular digestion or "exophagy".

In the st rad, the number of immature lysosomes and the overall number of lysosomes within microglia were significantly higher on day 7 p.i. compared with those on day $0(P<0.05)$, whereas no significant differences were seen for the other organelles (Table 4; Fig. 5a,b). Moreover, microglia-associated extracellular digestion was significantly higher on day 7 p.i. compared with that on day 0 ( $P<0.01$; Table 4; Fig. $5 b)$. Microglial interactions with synaptic elements, myelin, neurons, astrocytes, blood vessels, as well as myelin debris and extracellular space pockets remained unchanged after infection. These results suggest an overall increase in microglial phagolysosomal activities in the st rad of the dorsal hippocampus CA1.

In the st lac mol, the number and alterations of microglial organelles per cell were not significantly affected during ZIKV infection (Table 4). Microglial interactions with postsynaptic dendritic spines were significantly decreased on day 7 p.i. compared with those on day 0 $(P<0.05)$ but not those with presynaptic axon terminals, which may indicate a reduction of microglia-mediated neuronal postsynaptic remodeling (Table 4; Fig. 5c,d). The interactions between microglial cells and myelinated axons, neurons, astrocytes, blood vessels, myelin debris, and extracellular space pockets were not affected during ZIKV infection. However, microglia made less contact with degraded myelin on day 7 p.i. compared with that on day $0(P=0.05)$ (Table 4; Fig. 5c,d). Microglial association with extracellular debris or degraded elements was also significantly higher on day 7 p.i. compared with that on day $0(P<0.05)$ (Table 4; Fig. $5 \mathrm{c}, \mathrm{d})$. These results suggest that microglial cells are involved in phagocytic activities, extracellular digestion, and remodeling of postsynaptic elements during ZIKV infection of the young adult mouse brain.

\section{Depletion of microglia affects body weight gain and survival after ZIKV challenge}

We first evaluated the effect of PLX5622 on the number of microglial cells and blood monocytes in TRIF $^{-1-}$ xIPS- $1^{-1-}$ mice after 10 days of treatment. The immunofluorescence labeling of $\mathrm{Iba}^{+} / \mathrm{TMEM}^{+}$ microglia was decreased in the st rad of the dorsal hippocampus CA1 of PLX5622-treated compared with that of untreated mice (Fig. 6a). The number of $\mathrm{Iba}^{+} /$ $\mathrm{TMEM}^{+}$microglial cells in the st rad and st lac mol was respectively reduced by $81.9 \%$ and $79.4 \%$ after the pharmacological depletion. In contrast, the percentage of $\mathrm{CD} 45^{\text {high }} / \mathrm{CD} 11 \mathrm{~b}^{+} / \mathrm{Ly}_{6 \mathrm{C}^{+}}$monocytes to CD $45^{+}$ cells evaluated by flow cytometry was almost similar in treated and untreated mice $(9.5 \pm 1.0 \%$ versus $8.0 \pm 0.5 \%$ ) (data not shown) suggesting that PLX5622 did not affect the total number of monocytes in the blood.

In another experiment, we evaluated the effect of a microglial depletion with PLX5622 on the outcome of ZIKV infection in young adult mice. A lower increase in body weight was seen in mice treated with PLX5622 compared with that in untreated controls during the 10-day monitoring period (Fig. 6b). Furthermore, one 

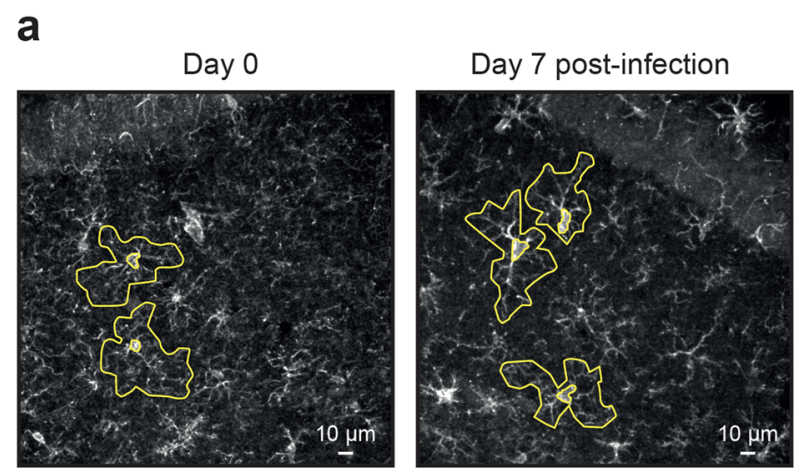

Day 10 post-infection
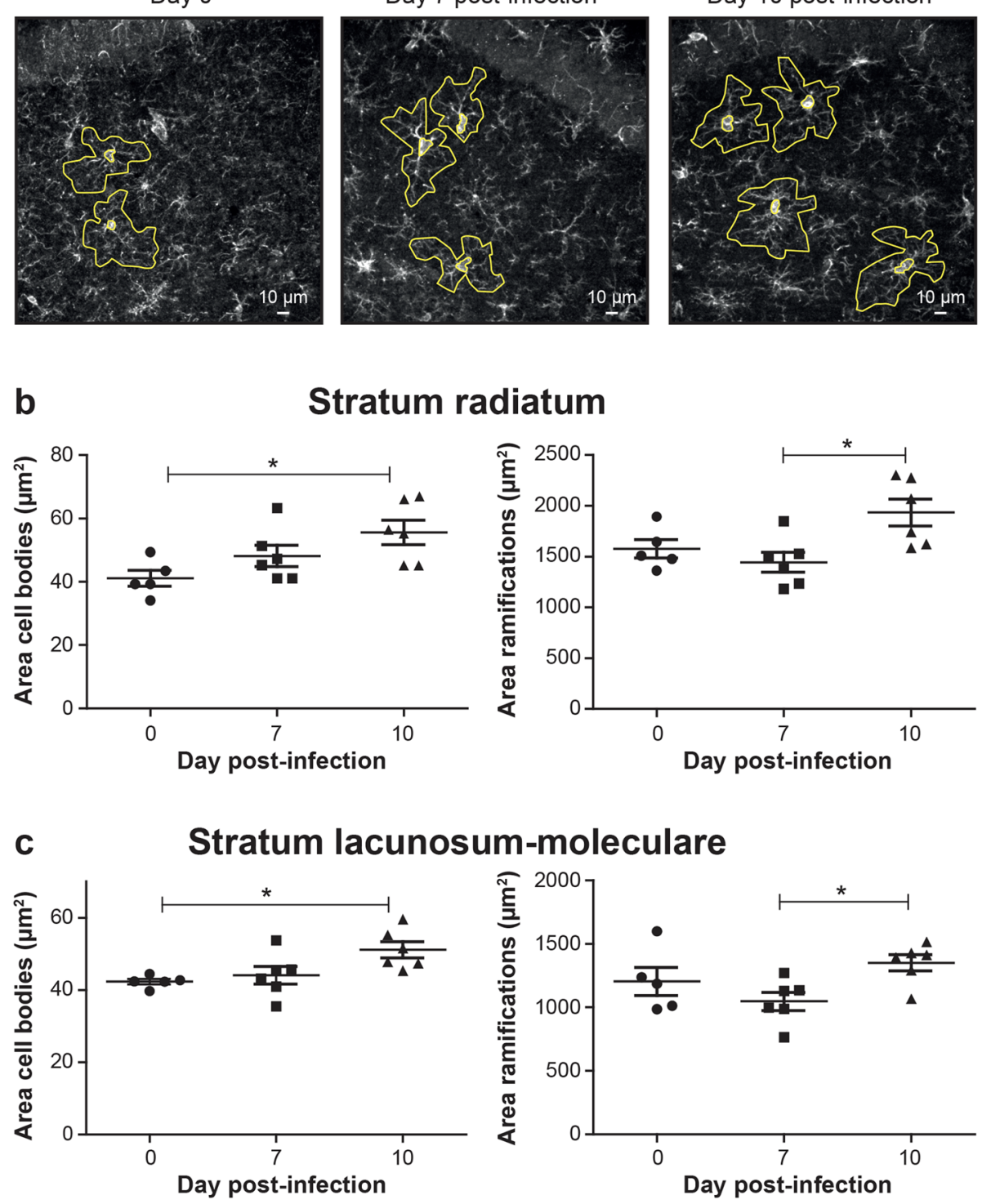

Fig. 4 Morphology of Iba $1^{+} / T M E M 119^{+}$microglial cells in the dorsal hippocampus CA1 after ZIKV challenge. a Representative micrographs with examples of tracing around $\mathrm{Iba} 1^{+} / \mathrm{TMEM} 119^{+}$microglia (using the $\mathrm{Iba} 1^{+}$channel) in the st rad on day 0 (noninfected), 7, and 10 post-infection that were used to calculate the areas of cell bodies and arborizations. Scale bars on the picture are equivalent to $10 \mu \mathrm{m}$. $\mathbf{b}-\mathbf{c}$ Areas of cell bodies (left) and areas of ramifications (right) of $\mathrm{Iba} 1^{+} / \mathrm{TMEM} 119^{+}$microglia in the st rad (b) and st lac mol (c). Results are the mean \pm SEM of 17 to 21 microglial cells per animal for a total of 5-6 mice per time point. Statistical analysis was performed using a one-way ANOVA with Tukey's multiple comparison test. Statistically different results between indicated groups are presented as follows: ${ }^{*} P<0.05$

of the 3 mice in the PLX5622-treated group died from the infection on day 10 p.i. (the brain was harvested to determine the viral RNA load), but none of the 3 control mice died. In both groups, the viremia was higher on day 3 p.i. and decreased thereafter (Fig. 6c). In untreated mice, the brain viral load reached a peak value on day 7 and decreased on day 10 p.i. (Fig. 6d).
In mice treated with PLX5622, the brain viral load increased from days 3 to 7 , and remained similar on day 10 p.i. The brain viral load was slightly higher in PLX5622-treated compared with that in untreated mice $\left(2.8 \times 10^{10}\right.$ versus $8.5 \times 10^{8}$ viral genome copy numbers), but this was not statistically significant possibly due to the low number of mice per group. 
Table 3 Morphological parameters of Iba1 ${ }^{+} / \mathrm{TMEM} 119^{+}$microglia in both layers of the dorsal hippocampus CA1

\begin{tabular}{|c|c|c|c|c|c|c|}
\hline \multirow[t]{2}{*}{ Parameters } & \multicolumn{3}{|c|}{ Stratum radiatum } & \multicolumn{3}{|c|}{ Stratum lacunosum-moleculare } \\
\hline & $\begin{array}{l}\text { Day } 0 \\
\text { Mean } \pm \text { SEM }\end{array}$ & $\begin{array}{l}\text { Day } 7 \text { p.i. } \\
\text { Mean } \pm \text { SEM }\end{array}$ & $\begin{array}{l}\text { Day } 10 \text { p.i. } \\
\text { Mean } \pm \text { SEM }\end{array}$ & $\begin{array}{l}\text { Day } 0 \\
\text { Mean } \pm \text { SEM }\end{array}$ & $\begin{array}{l}\text { Day } 7 \text { p.i. } \\
\text { Mean } \pm \text { SEM }\end{array}$ & $\begin{array}{l}\text { Day } 10 \text { p.i. } \\
\text { Mean } \pm \text { SEM }\end{array}$ \\
\hline Cell area $\left(\mu m^{2}\right)$ & $239.6 \pm 19.0$ & $250.3 \pm 15.4$ & $247.9 \pm 12.9$ & $146.8 \pm 10.7$ & $160.0 \pm 93.5$ & $150.2 \pm 10.9$ \\
\hline Soma area $\left(\mu m^{2}\right)$ & $41.08 \pm 2.55$ & $48.18 \pm 3.40$ & $55.57 \pm 3.89^{*}$ & $42.30 \pm 0.76$ & $44.06 \pm 2.47$ & $51.12 \pm 2.22^{*}$ \\
\hline Soma perimeter ( $\mu \mathrm{m})$ & $25.18 \pm 0.92$ & $27.74 \pm 1.29$ & $29.62 \pm 1.15(P=0.0574)$ & $25.35 \pm 0.26$ & $26.16 \pm 0.92$ & $28.36 \pm 0.68^{*}$ \\
\hline Arbor area $\left(\mu m^{2}\right)$ & $1576.2 \pm 90.5$ & $1443.2 \pm 98.1$ & $1931.5 \pm 132.2^{\#}$ & $1204.2 \pm 110.0$ & $1046.9 \pm 70.8$ & $1351.6 \pm 63.8^{\#}$ \\
\hline Arbor perimeter ( $\mu \mathrm{m})$ & $186.0 \pm 8.5$ & $187.4 \pm 11.1$ & $227.0 \pm 11.8(P=0.0505)^{\#}$ & $163.4 \pm 12.2$ & $158.0 \pm 7.7$ & $185.2 \pm 4.6$ \\
\hline Morphological index (a.u.) & $0.028 \pm 0.001$ & $0.036 \pm 0.001$ & $0.031 \pm 0.003$ & $0.041 \pm 0.003$ & $0.046 \pm 0.002$ & $0.041 \pm 0.002$ \\
\hline Circularity soma (a.u.) & $0.814 \pm 0.009$ & $0.794 \pm 0.019$ & $0.794 \pm 0.010$ & $0.830 \pm 0.008$ & $0.810 \pm 0.012$ & $0.800 \pm 0.011$ \\
\hline Solidity soma (a.u.) & $0.904 \pm 0.005$ & $0.902 \pm 0.006$ & $0.899 \pm 0.004$ & $0.916 \pm 0.003$ & $0.914 \pm 0.005$ & $0.914 \pm 0.005$ \\
\hline Aspect ratio soma (a.u.) & $1.653 \pm 0.027$ & $1.712 \pm 0.053$ & $1.638 \pm 0.045$ & $1.611 \pm 0.049$ & $1.725 \pm 0.057$ & $1.757 \pm 0.054$ \\
\hline Roundness soma (a.u.) & $0.651 \pm 0.013$ & $0.626 \pm 0.015$ & $0.649 \pm 0.015$ & $0.666 \pm 0.013$ & $0.620 \pm 0.017$ & $0.621 \pm 0.013$ \\
\hline Circularity arbor (a.u.) & $0.581 \pm 0.015$ & $0.538 \pm 0.024$ & $0.487 \pm 0.035$ & $0.572 \pm 0.031$ & $0.542 \pm 0.017$ & $0.509 \pm 0.014$ \\
\hline Solidity arbor (a.u.) & $0.847 \pm 0.007$ & $0.827 \pm 0.012$ & $0.804 \pm 0.018$ & $0.847 \pm 0.013$ & $0.828 \pm 0.007$ & $0.810 \pm 0.008^{*}$ \\
\hline Aspect ratio arbor (a.u.) & $1.498 \pm 0.047$ & $1.594 \pm 0.031$ & $1.478 \pm 0.044$ & $1.641 \pm 0.047$ & $1.757 \pm 0.037$ & $1.567 \pm 0.051^{\#}$ \\
\hline Roundness arbor (a.u.) & $0.693 \pm 0.020$ & $0.657 \pm 0.010$ & $0.706 \pm 0.016$ & $0.643 \pm 0.017$ & $0.612 \pm 0.008$ & $0.670 \pm 0.021^{\#}$ \\
\hline
\end{tabular}

a.u., arbitrary units; p.i., post-infection; SEM, standard error of the mean

Results are the mean \pm SEM of 17-21 microglia per animal for a total of 5-6 mice per time point

Statistical analyses were performed using a one-way analysis of variance with Tukey's multiple comparison test. ${ }^{*} P<0.05$ day 10 compared with day 0 (noninfected mice); ${ }^{\#} P<0.05$ day 10 compared with day 7 p.i.. Both are indicated in bold

\section{Depletion of microglia increases the number of neurons and astrocytes labeled for ZIKV antigens}

In order to determine the impact of microglia on the control of viral infection, we used scanning electron microscopy to evaluate the cellular localization of ZIKV envelope antigens labeled with immunogold in the st rad and st lac mol layers of the dorsal hippocampus CA1 of mice treated or not with PLX5622. As expected from the brain viral load, the total number of cells with nanogold particles increased in the st rad (17 versus 9) and st lac mol (35 versus 21) after the pharmacological depletion of microglia compared with untreated mice (Table 5). More specifically, after microglial depletion, the percentages of neurons (58.8\% in depleted versus $22.2 \%$ in non-depleted mice) and astrocytes ( $80.0 \%$ versus $23.8 \%$ ) immunolabeled for ZIKV antigens were increased in the st rad and st lac mol, respectively. In contrast, the percentages of pericytes containing immunogold particles $(0.0 \%$ versus $23.8 \%$ ) decreased in the st lac mol. The percentages of other perivascular cells with nanogold particles were reduced in both layers $(0.0 \%$ versus $22.2 \%$ in the st rad and $5.7 \%$ versus $23.8 \%$ in the st lac $m o l$ ). Overall, the percentages of parenchymal cells with nanogold particles increased (94.1\% versus $77.8 \%$ in the st rad and $91.4 \%$ versus $42.9 \%$ in the st lac $\mathrm{mol}$ ), whereas the percentage of perivascular cells decreased (5.9\% versus $22.2 \%$ in the st rad and $8.6 \%$ versus $57.1 \%$ in the st lac $\mathrm{mol}$ ) in mice depleted in microglia suggesting a shift in the cell types with ZIKV antigens (Table 5; Fig. 7a,b). The percentages of oligodendrocytes, microglial cells, and endothelial cells containing immunogold particles remained relatively unchanged after the pharmacological depletion of microglia.

\section{Depletion of microglia increases viral replication in neurons and astrocytes as well as phagocytic activity of astrocytes}

In order to elucidate the role of microglia in the pathogenesis of brain infection by ZIKV, we determined the subcellular localization of viral envelope antigens stained by immunogold in different brain cell types in mice treated or not with PLX5622. In untreated mice, nanogold particles were found exclusively at the plasma membrane and within endosomes of microglia, indicating their active contribution to the elimination of ZIKVinfected cells by phagocytosis (Supplementary Table 3). In PLX5622-treated mice, the number of nanogold particles was higher in the cytoplasm (9 versus 3 in the st lac $\mathrm{mol}$ ), endoplasmic reticulum (5 versus 1 in the st rad), and endosomes (17 versus 2 in the st rad and 5 versus 0 in the st lac mol) of neurons suggesting an increased viral replication. In astrocytes, the number of nanogold particles were also higher in the cytoplasm (40 versus 1 in the st lac mol) as well as in the endosomes (10 versus 0 in the st rad and 31 versus 7 in the st lac mol) (Supplementary Table 3; Fig. 7a,b) of astrocytes suggesting enhanced viral 
Table 4 Microglial ultrastructure in both layers of the dorsal hippocampus CA1

\begin{tabular}{|c|c|c|c|c|c|}
\hline \multirow[t]{3}{*}{ Parameters } & & \multicolumn{4}{|c|}{ Number per cell (mean \pm SEM) } \\
\hline & & \multicolumn{2}{|c|}{ Stratum radiatum } & \multicolumn{2}{|c|}{ Stratum lacunosum-moleculare } \\
\hline & & Day 0 & Day 7 p.i. & Day 0 & Day 7 p.i. \\
\hline \multicolumn{6}{|c|}{ Organelles of phagolysosomal pathway within microglia } \\
\hline \multirow[t]{3}{*}{ Lysosomes } & Immatures & $0.031 \pm 0.031$ & $0.406 \pm 0.126^{*}$ & $0.313 \pm 0.123$ & $0.306 \pm 0.087$ \\
\hline & Matures & $0.094 \pm 0.052$ & $0.250 \pm 0.078$ & $0.344 \pm 0.124$ & $0.333 \pm 0.089$ \\
\hline & Total & $0.125 \pm 0.059$ & $0.656 \pm 0.159^{*}$ & $0.656 \pm 0.159$ & $0.639 \pm 0.139$ \\
\hline \multirow[t]{3}{*}{ Endosomes } & Empty & $0.094 \pm 0.052$ & $0.188 \pm 0.105$ & $0.063 \pm 0.043$ & $0.222 \pm 0.081$ \\
\hline & With content & $0.531 \pm 0.180$ & $0.281 \pm 0.112$ & $0.719 \pm 0.175$ & $0.472 \pm 0.116$ \\
\hline & Total & $0.625 \pm 0.178$ & $0.469 \pm 0.201$ & $0.781 \pm 0.189$ & $0.694 \pm 0.178$ \\
\hline Lipidic inclusions & & $0.156 \pm 0.079$ & $0.250 \pm 0.089$ & $0.250 \pm 0.100$ & $0.417 \pm 0.108$ \\
\hline \multicolumn{6}{|c|}{ Altered organelles within microglia } \\
\hline ER/Golgi & Dilation & $0.875 \pm 0.059$ & $0.781 \pm 0.074$ & $0.906 \pm 0.052$ & $0.944 \pm 0.039$ \\
\hline \multirow[t]{5}{*}{ Mitochondria } & Elongated & $0.188 \pm 0.095$ & $0.438 \pm 0.134$ & $0.594 \pm 0.173$ & $0.417 \pm 0.128$ \\
\hline & Holy & $0.094 \pm 0.052$ & $0.094 \pm 0.069$ & $0.094 \pm 0.052$ & $0.139 \pm 0.058$ \\
\hline & Donut-shaped & $0.031 \pm 0.031$ & $0 \pm 0$ & $0.031 \pm 0.031$ & $0.055 \pm 0.039$ \\
\hline & Abnormal & $0.281 \pm 0.103$ & $0.375 \pm 0.117$ & $0.688 \pm 0.182$ & $0.611 \pm 0.175$ \\
\hline & Total (normal + altered) & $2.188 \pm 0.319$ & $3.531 \pm 0.741$ & $3.531 \pm 0.552$ & $3.833 \pm 0.531$ \\
\hline \multicolumn{6}{|c|}{ Contacts of microglia with microenvironment } \\
\hline \multirow{2}{*}{$\begin{array}{l}\text { Synaptic elements } \\
\text { (neurons) }\end{array}$} & Pre-synaptic & $4.406 \pm 0.638$ & $3.375 \pm 0.451$ & $5.813 \pm 0.595$ & $4.944 \pm 0.569$ \\
\hline & Post-synaptic & $1.875 \pm 0.361$ & $2.094 \pm 0.352$ & $3.219 \pm 0.380$ & $2.389 \pm 0.439^{*}$ \\
\hline \multirow{2}{*}{$\begin{array}{l}\text { Myelin } \\
\text { (neurons) }\end{array}$} & Myelinated axons & $0.344 \pm 0.115$ & $0.313 \pm 0.138$ & $0.625 \pm 0.290$ & $0.333 \pm 0.098$ \\
\hline & Degraded myelin & $0.469 \pm 0.149$ & $0.969 \pm 0.260$ & $1.250 \pm 0.220$ & $0.778 \pm 0.200(P=0.05)$ \\
\hline \multirow[t]{3}{*}{ Brain cells or vasculature } & Neuronal cell bodies & $0.189 \pm 0.095$ & $0.063 \pm 0.043$ & $0.031 \pm 0.031$ & $0.083 \pm 0.047$ \\
\hline & Astrocytic cell bodies & $0.031 \pm 0.031$ & $0.031 \pm 0.031$ & $0.219 \pm 0.087$ & $0.306 \pm 0.078$ \\
\hline & Blood vessels & $0.156 \pm 0.065$ & $0.094 \pm 0.052$ & $0.156 \pm 0.079$ & $0.139 \pm 0.058$ \\
\hline Myelin debris & & $0.500 \pm 0.135$ & $0.594 \pm 0.184$ & $0.906 \pm 0.217$ & $0.722 \pm 0.181$ \\
\hline Extracellular space & & $3.935 \pm 0.510$ & $2.625 \pm 0.399$ & $3.531 \pm 0.557$ & $2.750 \pm 0.517$ \\
\hline Extracellular digestion & & $0.438 \pm 0.174$ & $1.194 \pm 0.199^{* *}$ & $0.281 \pm 0.121$ & $0.639 \pm 0.121^{*}$ \\
\hline
\end{tabular}

ER/Golgi, endoplasmic reticulum and Golgi apparatus cisterna; p.i., post-infection; SEM, standard error of the mean

Results are the mean \pm SEM of 32-33 microglia per time point (6-10 microglia per animal for a total of 4 mice per time point) in the stratum radiatum and of 32-36 microglia per time point (7-10 microglia per animal for a total of 4 mice per time point) in the stratum lacunosum-moleculare

Statistical analyses were performed using a nonparametric Mann-Whitney comparison test. Results that are statistically different compared to day 0 (noninfected mice) are presented as follows: ${ }^{*} P<0.05 ;{ }^{* *} P<0.01$ and are indicated in bold

replication. In the endosomes of neurons, nanogold particles were not associated with digested material (Fig. 7c), indicating their involvement in ZIKV entry into cells by endocytosis. In contrast, endosomes of astrocytes sometimes contained nanogold particles together with partially digested cellular debris (Fig. 7c), suggesting that these cells could partially compensate for the phagocytic elimination of ZIKV-infected cells, in the almost-complete absence of microglia. The number of nanogold particles in the Golgi apparatus, at the plasma membrane, mitochondrial membrane, nuclear membrane, and in the nucleus remained similar for all other cell types investigated in both layers of the dorsal hippocampus. Overall, these results indicate that microglia actively participate to the control of ZIKV replication and/or elimination in young adult mouse brain, as illustrated by enhanced accumulation of immunogold particles within organelles involved in viral replication. Furthermore, phagocytic elimination of ZIKV-infected cells is partly compensated by astrocytes in the almost-complete absence of the main phagocytes, microglia.

\section{Discussion}

Contemporary ZIKV strains can invade the CNS of adult individuals following infection and are associated with a broad spectrum of neurological disorders. However, the mechanisms involved in the infection of the mature CNS are not yet elucidated. In this study, we evaluated the 
a

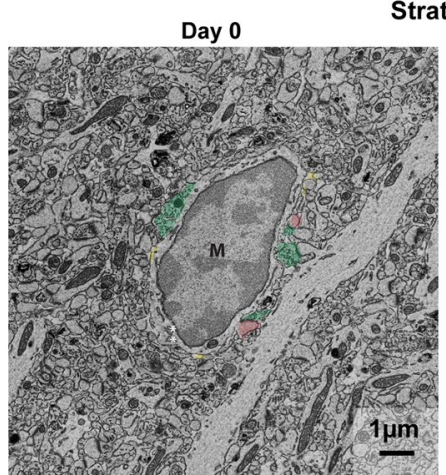

b

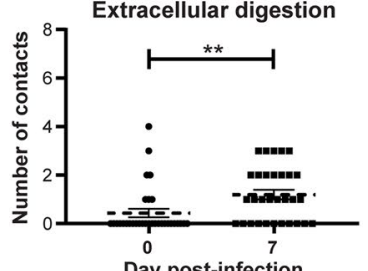

Stratum radiatum

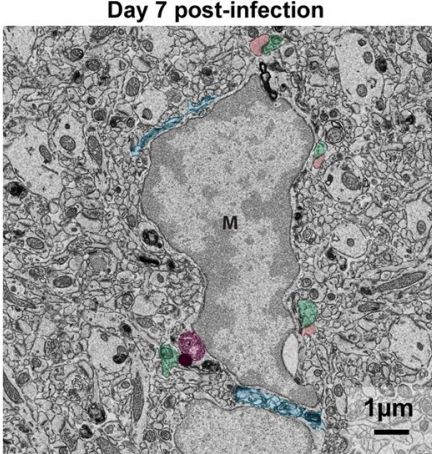

Immature lysosomes

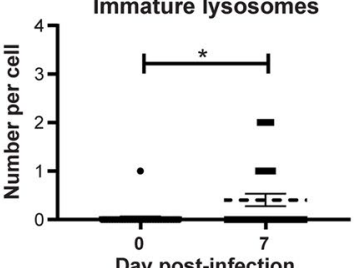

C

Stratum lacunosum-moleculare

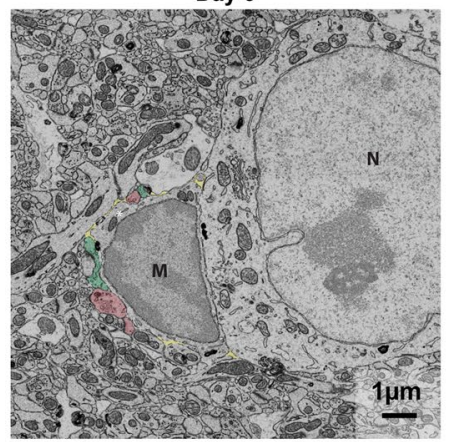

Day 7 post-infection

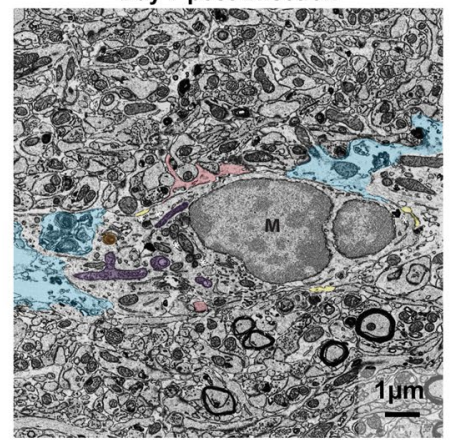

d
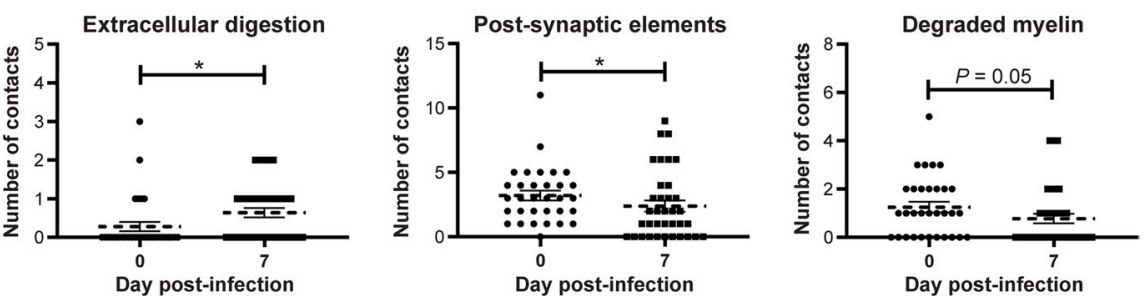

Fig. 5 Ultrastructural analysis of the dorsal hippocampus CA1 of mice infected with ZIKV. a Example pictures of microglia in the stratum radiatum of noninfected (day 0 ) and infected mice (day 7 post-infection) highlighting changes in $\mathbf{b}$ extracellular digestion and the number of immature lysosomes per cell during ZIKV infection. Results are the mean \pm SEM of 32-33 microglia per time point (6-10 microglia per animal for a total of 4 mice per time point). c Example pictures of microglia in the stratum lacunosum-moleculare of noninfected (day 0 ) and infected mice (day 7 post-infection) showing changes of $\mathbf{d}$ extracellular digestion and contacts with postsynaptic elements and degraded myelin per cell during ZIKV infection. Results are the mean \pm SEM of 32-36 microglia per time point (7-10 microglia per animal for a total of 4 mice per time point). On the example pictures, cell types are identified by a capital letter; $M$, microglia; $N$, neuron. Structural elements on the example pictures are identified by a mix of pseudo-coloring and text annotation; presynaptic elements (green), postsynaptic elements (red), extracellular space (yellow), extracellular digestion (light blue), immature lysosomes (pink), mature lysosomes (orange), abnormal mitochondria (purple), and dilated endoplasmic reticulum (white asterisk). Scale bars on the picture are equivalent to $1 \mu \mathrm{m}$. Statistical analyses were performed using a nonparametric Mann-Whitney comparison test. Results that are statistically different between indicated groups are shown as follows: ${ }^{*} P<0.05$; ${ }^{* *} P<0.01$ 


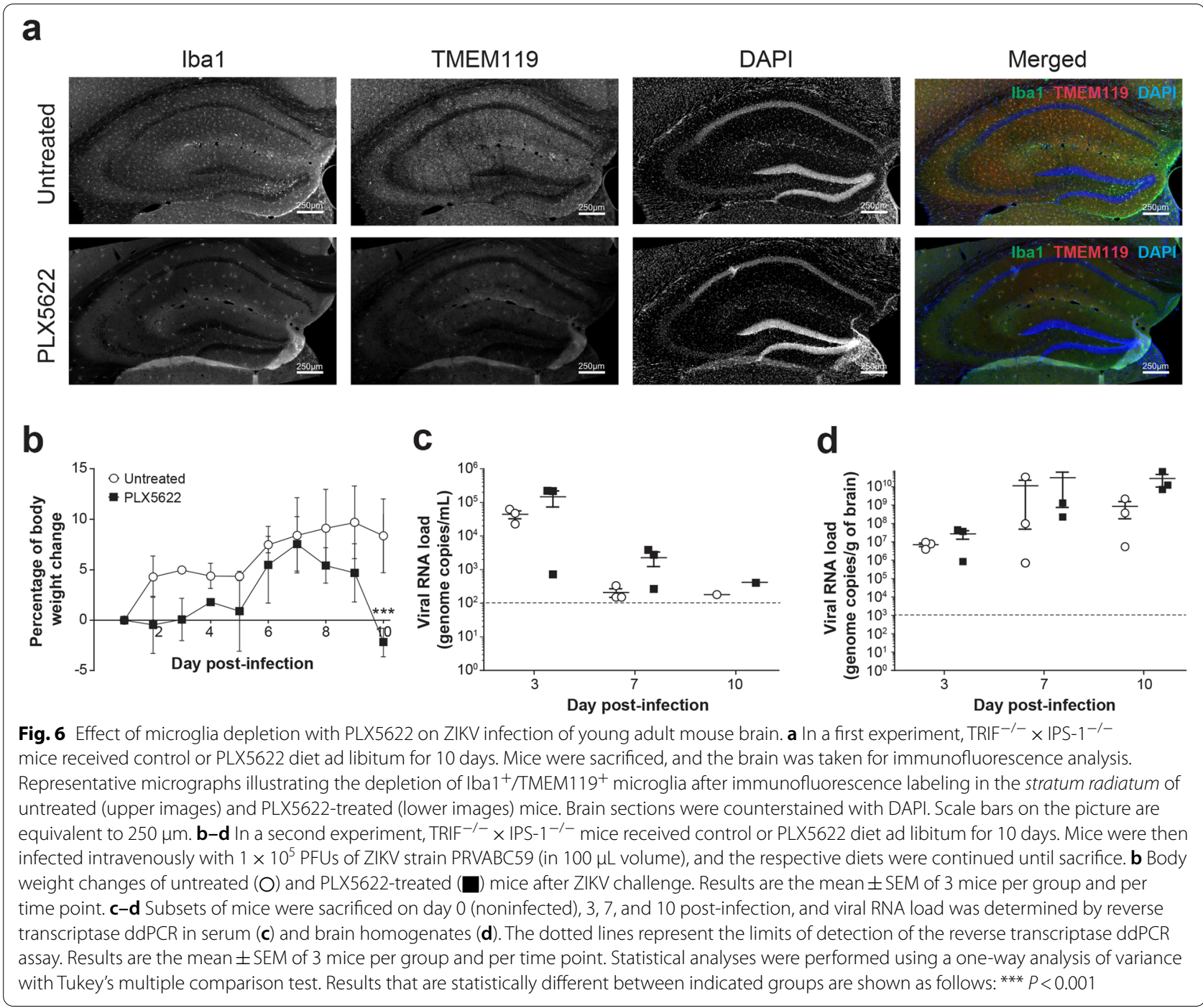

distribution of a contemporary ZIKV strain in the mature brain in a nonlethal immunodeficient mouse model as well as the role played by microglia during the infection. Our results demonstrate that ZIKV mostly localizes in the dorsal hippocampus region of the brain, which plays important roles in learning and memory functions [51]. In addition, microglial cells exhibit morphology characteristics of a reactive state, and display increased phagocytic activities and extracellular digestion during the infection. Pharmacological depletion of microglia amplifies the viral infection as shown by an increase in the number of neurons and astrocytes with ZIKV envelope antigens stained by immunogold in the dorsal hippocampus CA1. In neurons and astrocytes, nanogold particles are found in the compartment involved in ZIKV replication, such as cytoplasm, endoplasmic reticulum, and endosomes $[52,53]$. In the absence of microglia, the phagocytic elimination of ZIKV-infected cells is partly compensated by astrocytes as indicated by the increased number of nanogold particles associated with digested debris in the endosomal compartment.

Despite a lack of clinical signs of the disease and effect on body weight, young adult $\mathrm{TRIF}^{-/-} \mathrm{xIPS}-1^{-1-}$ mice infected intravenously with the contemporary ZIKV strain PRVABC59 developed a viremia and a brain viral load as previously shown by our group [21]. Of note, WT C57BL/6 mice exhibited a transient viremia, and no viral load could be detected in their brain. Immunoperoxidase staining of viral envelope antigens indicated that ZIKV was distributed in several regions of the brain, and especially in the dorsal hippocampus. Several studies have already reported that ZIKV preferentially targets the hippocampus region of adult [8, 20, 30, 54, 55] and neonate mouse brains [56]. The wider distribution of ZIKV across the brain in our model compared with that seen in immunocompetent mice could result from the 
Table 5 Cellular localization of Zikaf virus antigens labeled with immunogold in both layers of the dorsal hippocampus CA1

\begin{tabular}{|c|c|c|c|c|}
\hline \multirow[t]{3}{*}{ Cell Types } & \multicolumn{4}{|c|}{ Number of cells with at least 2 nanogold particles (\%) } \\
\hline & \multicolumn{2}{|c|}{ Not treated with PLX5622 } & \multicolumn{2}{|c|}{ Treated with PLX5622 } \\
\hline & st rad & st lac mol & st rad & st lac mol \\
\hline Neurons & $2(22.2)$ & $3(14.3)$ & $10(58.8)$ & $4(11.4)$ \\
\hline Astrocytes & $3(33.3)$ & $5(23.8)$ & $4(23.5)$ & $28(80.0)$ \\
\hline Oligodendrocytes & $0(0.0)$ & $0(0.0)$ & $1(5.9)$ & $0(0.0)$ \\
\hline Microglia & $2(22.2)$ & $1(4.8)$ & $1(5.9)$ & $0(0.0)$ \\
\hline Parenchymal cells & $7(77.8)$ & $9(42.9)$ & $16(94.1)$ & $32(91.4)$ \\
\hline Endothelial cells & $0(0.0)$ & $2(9.5)$ & $0(0.0)$ & $1(2.9)$ \\
\hline Pericytes & $0(0.0)$ & $5(23.8)$ & $1(5.9)$ & $0(0.0)$ \\
\hline Other perivascular cells & $2(22.2)$ & $5(23.8)$ & $0(0.0)$ & $2(5.7)$ \\
\hline Perivascular cells & $2(22.2)$ & $12(57.1)$ & $1(5.9)$ & $3(8.6)$ \\
\hline Total cells & $9(100.0)$ & $21(100.0)$ & $17(100.0)$ & $35(100.0)$ \\
\hline
\end{tabular}

$\%$ of a specific cell type to the total number of cells containing nanogold particles; st rad, stratum radiatum; st lac mol, stratum lacunosum-moleculare. In the st rad, 36 pictures (7-13 per animal) for untreated and 47 pictures (9-14 per animal) for treated mice were analyzed. In the st lac mol, 51 pictures (8-16 per animal) for untreated and 59 pictures (9-22 per animal) for treated mice were analyzed. $n=4$ mice per group

altered production in type I IFN as suggested by others $[8,20]$. Nevertheless, our results confirm that ZIKV targets learning and memory-related regions of the brain [8] as other flaviviruses such as West Nile virus [57] and Japanese encephalitis virus [58]. In this respect, a report described the case of a ZIKV-positive adolescent presenting cognitive impairment [59].

Scanning electron microscopy analysis revealed that ZIKV envelope antigens labeled with immunogold were detected in astrocytes, neurons, pericytes, microglia as well as in other vascular cells in the st rad and st lac mol layers of the dorsal hippocampus CA1. The cell types that are infected by ZIKV in the brain widely differ according to the mouse model and route of virus inoculation used and still remain unclear. A study demonstrated that astrocytes constitute the main cell type infected by ZIKV in the brain of susceptible mice [60]. More recently, ZIKV was reported to replicate in neurons of adult human cortical tissues and mature brain of immunocompetent mice $[8$, 20]. Other studies also described the presence of ZIKV envelope antigens in pericytes [61] and blood vessels [62]. Finally, microglia isolated from human fetal brain and mouse brain can be infected by ZIKV and promote the release of pro-inflammatory cytokines [63-66]. We cannot exclude, however, that the lack of type I IFN secretion in our murine model could have modulated the susceptibility of the different brain cells to ZIKV infection.

ZIKV infection increases the levels of a series of cytokines (IL-1 $\alpha$, IL-6, IL-9, IL-10, IL-12p70, and IFN$\gamma)$ and chemokines (CCL2, CCL3, CCL4, CCL5, CCL11, and CXCL1) in mouse brain. Microglia could be the main cells responsible for producing inflammatory mediators after ZIKV infection, but it is suggested that neurons [67] and pericytes [68] could also be potential sources. ZIKV induces a pro-inflammatory response through the release of IL- 6 and IL- 9 as well as an anti-inflammatory response through IL-10. Astrocytes and neurons could produce CCL2 which is involved in monocyte recruitment and induces the reactivity of microglia during infection [69]. CXCL1 is involved in neutrophil migration during West Nile virus pathogenesis [70]. The release of CCL3, CCL4, and CCL5 may promote the recruitment and activation of $\mathrm{T}$ cells during viral infection of the brain [60]. ZIKV increases the production of IL-12p70, an inducer of IFN- $\gamma$ production by $\mathrm{T}$ cells [71]. It is suggested that IFN- $\gamma$ could signal through microglia [72] to induce cognitive dysfunction, including spatial learning defects, in adult mice that recovered from West Nile virus or ZIKV infection [55]. Finally, ZIKV promotes the release of CCL11 which was associated with a reduction of neurogenesis and cognitive functions in the hippocampus [73].

Microglia display diverse phenotypes depending on their function and interaction with their surrounding microenvironment [74]. Under normal physiological conditions, microglia adopt a surveying phenotype characterized by compact cell bodies and elongated ramification processes $[25,26]$. In case of CNS injury or infection with a pathogen, microglia transform in reactive states by withdrawing or further extending their processes, and enlarging their cell bodies sometimes leading to an amoeboid morphology [29, 75]. Immunofluorescence analyses revealed that $\mathrm{Iba}^{+} / \mathrm{TMEM}_{119^{+}}$microglial cells highly co-localize with ZIKV antigens in both layers of the dorsal hippocampus CA1. Although the density of microglia in these two regions was not affected after ZIKV challenge, microglial clustering increased in infected versus 


\section{a}

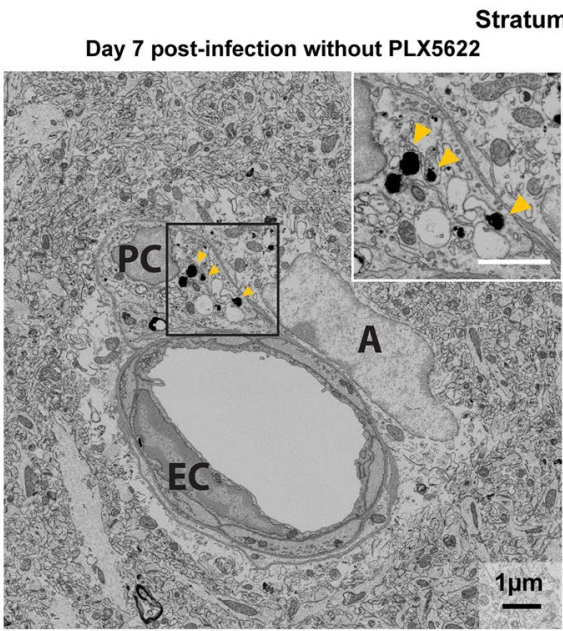

Day 7 post-infection with PLX5622

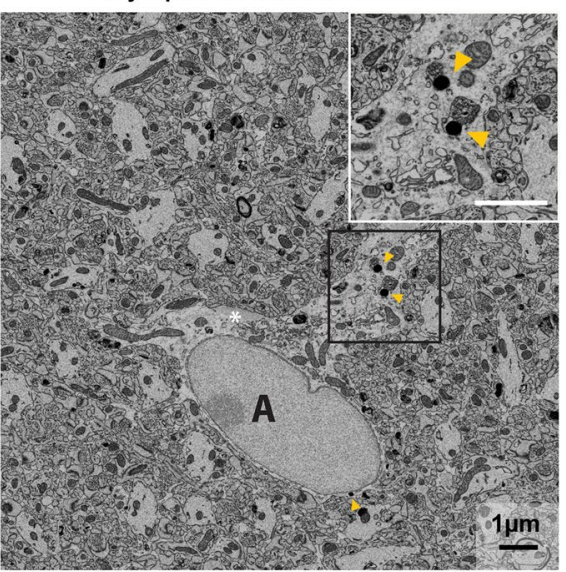

b

Stratum lacunosum-moleculare
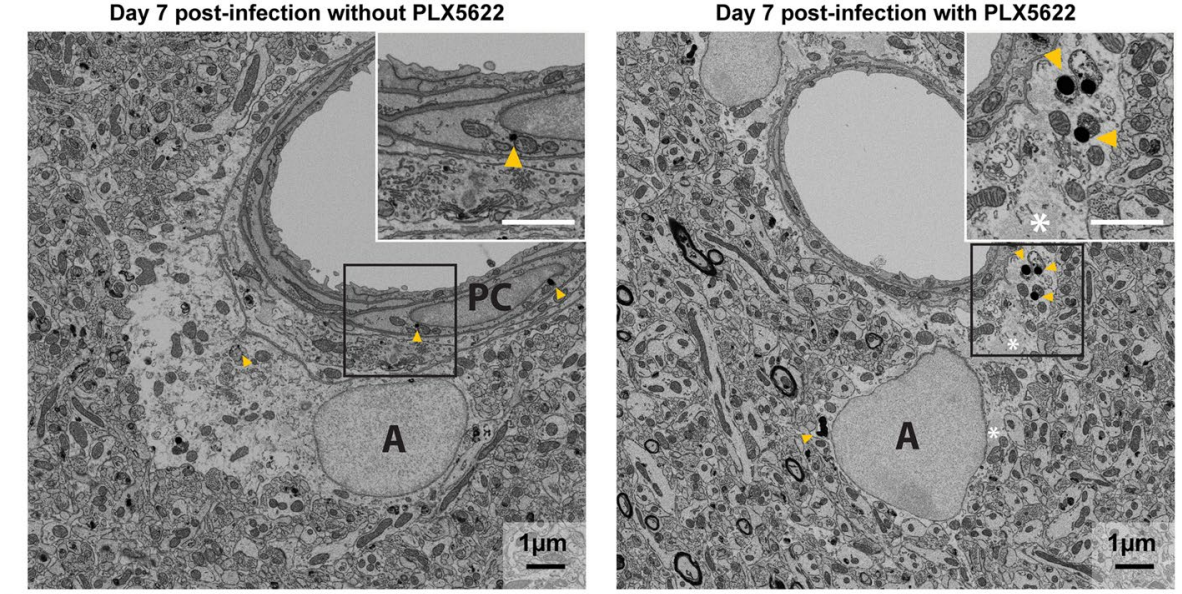

C
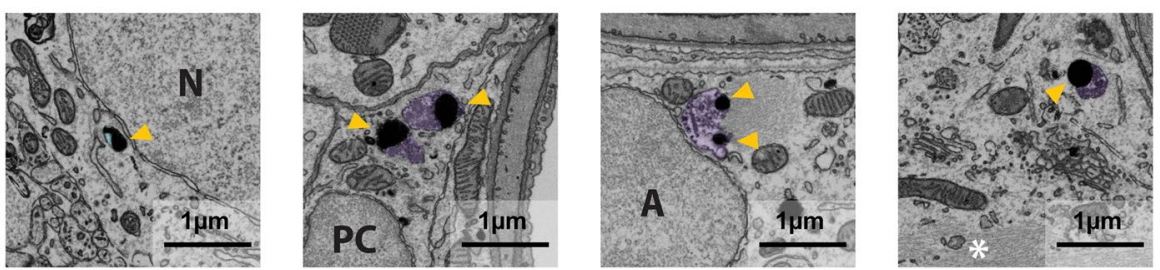

Fig. 7 Ultrastructural analysis of the dorsal hippocampus CA1 of mice depleted in microglia and infected with ZIKV. a The left picture shows immunogold particles in the cytoplasm, endosome, and mitochondria of a perivascular cell in the stratum radiatum of untreated mice on day 7 post-infection. The right picture shows immunogold particles in the endosome of an astrocyte in the stratum radiatum of PLX5622-treated mice on day 7 post-infection. $\mathbf{b}$ The left picture shows nanogold particles in the mitochondria and at the nuclear membrane of a perivascular cell in the stratum lacunosum-moleculare of untreated mice on day 7 post-infection. The right picture shows immunogold particles in the cytoplasm and endosome of an astrocyte in the stratum lacunosum-moleculare of PLX5622-treated mice on day 7 post-infection. Insert in the right corner of each picture shows the subcellular localization of nanogold particles. c Pictures illustrate differences in content of endosomes with nanogold particles in different cell types: from left to right, neuron, perivascular cell, and astrocytes (two pictures at the right) from the stratum lacunosum-moleculare. Endosomes are pseudo-colored to distinguish empty endosomes (light blue) from endosomes with digested content (light purple). On the example pictures, cell types are identified by a capital letter: $A$, astrocyte; $E C$, endothelial cell, and $P C$, perivascular cell. Astrocytic intermediate filaments are also identified by a white asterisk (*). Nanogold particles, which stain ZIKV antigens, are highlighted by yellow arrowheads. Scale bars on the picture are equivalent to $1 \mu \mathrm{m}$ for the whole picture and for the insert

noninfected mice possibly as a result of innate immune activation [76]. It has been suggested that these primary microglial nodules could provide an environment for $\mathrm{T}$ cells leading to the formation of secondary nodules in which neurons are destroyed during viral encephalitis [77]. Furthermore, the cell body and arborization areas of microglia were significantly increased in infected versus noninfected mice. The enlargement of microglial cell 
body could result from the increased production of proinflammatory mediators in the brain and to the removal of cellular debris by phagocytosis or extracellular digestion, as observed in other contexts of brain injury [75, 78]. The increase in the ramification process may suggest that microglia enhance their surveillance and dynamic interaction with synaptic elements in the brain parenchyma [24, 79-81]. These characteristics are consistent with a reactivity or functional transformation of microglia during ZIKV infection as previously demonstrated in adult mouse brain [20] as well as in hippocampal slices of newborn mice [56].

Microglia have multiple functions including surveillance of the brain, elimination of superfluous synapses (pruning), as well as clearance of damaged neurons and myelin debris by phagocytosis [22, 82]. In this regard, altered microglial functions can be identified through a change in their interactions within their microenvironment at the ultrastructural level [24]. In the st lac mol, the interactions of microglial cells with postsynaptic dendritic spines, but not with presynaptic axon terminals, were significantly decreased on day 7 p.i. compared to noninfected mice, which may indicate a reduction of microglia-mediated neuronal postsynaptic remodeling in the active phase of infection [24]. These results may also suggest that microglia communication/interactions with postsynaptic elements is compromised, which could impact the maintenance of synaptic homeostasis following ZIKV infection of the brain [83]. Previous studies showed that $\mathrm{T}$ cells promote microglial elimination of postsynaptic elements by phagocytosis in the hippocampus CA3 after recovery from ZIKV infection [55]. Phagocytic inclusions or endosomes were also found in the cell bodies and processes of microglia. In the st rad, the number of immature lysosomes and the total number of lysosomes containing phagocytic or degraded materials were significantly increased in microglial cells of ZIKV-infected versus noninfected mice. These results demonstrate that microglia exhibit an enhanced capacity to phagocytose ZIKV-infected cells during brain infection. Dilation of the lumen of endoplasmic reticulum and Golgi apparatus, an ultrastructural marker of cellular stress, remained unchanged in microglia after ZIKV challenge. The number of lipidic inclusions which are actively formed in microglia responding to pro-inflammatory cytokines, and may thus represent a marker of cellular metabolic stress or an early hallmark of neuroinflammation [84], was increased in ZIKV-infected compared with that in noninfected mice, although the difference was not statistically significant. Following ZIKV challenge, microglia interacted differently with their microenvironment in the brain. Indeed, microglial cell bodies and processes were associated with an increased number of extracellular space pockets containing degraded elements or debris in both layers of the dorsal hippocampus CA1. These results suggest, for the first time to our knowledge, that microglia could play an important role in the removal of extracellular debris during ZIKV infection of the brain. It is suggested that microglia break down dead or dying neurons into pieces using exophagy before their phagocytic engulfment and digestion [46], hence allowing them to digest large debris and cells $[49,50]$. During brain injury or infection with a pathogen, another important feature of microglia is their capacity to migrate to damaged regions. Microglia can release cathepsins, heparinases, and metalloproteinases to modify the extracellular matrix and promote their migration/motility during neuroinflammation [85]. In this respect, we observed a trend for a decrease in microglia-associated extracellular space after ZIKV challenge, which could indicate a decrease in microglial dynamics associated with altered physiological functions.

Depletion of microglia led to an increase in the number of brain cells with ZIKV antigens stained by immunogold, especially neurons and astrocytes, in both layers of the dorsal hippocampus CA1. The number of immunogold particles was increased in cellular compartments involved in viral replication in neurons (cytoplasm, endoplasmic reticulum, and endosomes) and astrocytes (cytoplasm and endosomes) from both regions suggesting an enhanced replication of ZIKV in these cells $[52,53]$. This was reflected by a higher, although not significant, brain viral load in mice treated with PLX5622 compared with that in the untreated group on day 10 p.i. In line with our results, depletion of microglia with PLX5622 was also reported to increase the brain viral load in mouse models of infections caused by West Nile virus and Japanese encephalitis virus [86], vesicular stomatitis virus [87], mouse hepatitis virus [88] as well as in a pseudorabies virus model of herpes virus encephalitis [89]. In addition to its effect on microglial survival, it has been shown that PLX5622 may reduce B7 co-stimulatory signals on peripheral and brain antigen-presenting cells, which could limit reactivation of antiviral $\mathrm{CD}^{+} \mathrm{T}$ cells and reduce viral clearance [90].

Microglia are considered as the primary phagocytic cells in the brain, but astrocytes have also been shown to exhibit phagocytic activity after brain injury [91, 92]. Under normal physiological conditions, a dynamic cross talk between microglia and astrocytes coordinates their involvement in the phagocytosis of debris [93]. Due to their functional plasticity, astrocytes become partially responsible for debris removal in the absence of 
microglia [94, 95]. In our study, an increased number of nanogold particles together with digested material were detected in astrocytic endosomes suggesting that astrocytes could exert a beneficial phagocytic elimination role after microglial depletion. Overall, these results suggest that microglia are involved in the control of ZIKV replication and/or phagocytic elimination in the young adult mouse brain and that astrocytes could partially overcome the almost-complete absence of microglial cells by clearing virally infected cells by phagocytosis.

One limitation of this study is the use of mice deficient for the production of type I IFN instead of immunocompetent mice, which may have affected the distribution of ZIKV in the brain, as well as the cell types that were infected. However, these mice did not develop overt clinical signs of the disease and did not succumb to infection which allowed us to examine in detail the role played by microglia in the pathogenesis of ZIKV infection of young adult brain without the contribution of infiltrating peripheral monocytes. During the 2013-2017 epidemic, the increased number of adults presenting with neurological disorders was associated with contemporary strains of ZIKV. Nevertheless, it would be interesting to compare ZIKV strains belonging to Asian and African lineages in future studies as the latter was shown to exhibit a higher virulence in mouse models [96]. In addition, only female mice were used in our study, and a comparison with male mice could have been interesting due to the sex differences in microglia $[97,98]$ and immune response [99].

\section{Conclusions}

Our results show that microglial cell bodies and processes display morphological characteristics of a reactive state or functional transformation after ZIKV infection. Microglia were found to be responsible for both the phagocytosis and extracellular digestion of degraded elements and debris. Furthermore, pharmacological depletion of microglia with PLX5622 demonstrated that these cells are normally involved in the control of ZIKV replication and/or phagocytic elimination. In addition, astrocytes could eliminate ZIKV-infected cells by phagocytosis in the absence of microglia thus revealing a partial compensatory mechanism.

\footnotetext{
Abbreviations

ANOVA: Analysis of variance; CA1: Cornu ammoni 1; CCL: Chemokine (C-C motif) ligand; CD: Cluster of differentiation; CNS: Central nervous system; CSF: Cerebrospinal fluid; CXCL: Chemokine (CXC motif) ligand; DAB: Diaminobenzidine; ddPCR: Droplet digital PCR; G-CSF: Granulocyte colony-stimulating factor; Iba1: Ionized calcium-binding adaptor molecule 1; IFN: Interferon; IFNAR: Interferon alpha/beta receptor; IL: Interleukin; IPS-1: IFN- $\beta$ promoter stimulator 1; Ly6C: Lymphocyte antigen 6 complex; MDA-5: Melanoma
}

differentiation-associated gene 5; mRNA: Messenger RNA; NND: Nearest neighbor distance; NS5: Nonstructural protein 5; PB: Phosphate buffer; PBS: Phosphate-buffered saline; PFA: Paraformaldehyde; PFU: Plaque-forming units; p.i.: Post-infection; RIG-I: Retinoic acid-inducible gene I; RT: Room temperature; SEM: Standard error of the mean; STAT2: Signal transducer and activator of transcription 2; st lac mol: Stratum lacunosum-moleculare; st rad: Stratum radiatum; TBS: Tris-buffered saline; TBS-T: Tris-buffered saline containing 0.05\% Triton X-100; TLR3: Toll-like receptor 3; TMEM119: Transmembrane protein 119; TNF-a: Tumor necrosis factor-a; TRIF: Toll-interleukin-1 receptor domain-containing adaptor inducing IFN- $\beta$; WT: Wild type; ZIKV: Zika virus.

\section{Supplementary Information}

The online version contains supplementary material available at https://doi. org/10.1186/s12974-021-02221-z.

\section{Additional file 1. Supplementary methods.}

Additional file 2: Supplementary Table 1. Scoring system used to evaluate the extent of Zika virus antigen immunostaining in mouse brain.

Additional file 3: Supplementary Table 2. Ratios of mRNA copies of interferon- $\alpha /-\beta$ to housekeeping 185 ribosomal subunit in the brain of mice infected with Zika virus.

Additional file 4: Supplementary Table 3. Nanoscale subcellular localization of Zika virus antigens labeled with immunogold in both layers of the dorsal hippocampus CA1 of mice not treated or treated with PLX5622.

\section{Acknowledgements}

The authors would like to thank Julie-Christine Levesque from Bioimaging and Luminex technology platforms of the CHU de Québec-Université Laval Research Center for assistance in Bio-Plex system and Bio-Plex manager software and Michèle Orain from the Centre de recherche de I'Institut Universitaire de Cardiologie et de Pneumologie de Québec for image acquisition with the Hamamatsu NanoZoomer HT 2.0 slide scanner during immunohistochemistry analysis.

\section{Authors' contributions}

$W E, M B, J P, M E T$, and GB conceived and designed the study; WE, MB, FGI, OU, $M C V, N G$, and JC performed research; WE and MB analyzed data; WE, MB, JP, MET, and GB wrote the paper. The authors read and approved the final manuscript.

\section{Funding}

This study was supported by Foundation Grants from the Canadian Institutes of Health Research (grant no. 148361 to G.B.; grant no. 353750 to M.E.T.) as well as a Discovery grant from the Natural Sciences and Engineering Research Council (grant no. RGPIN-2014-05308 to M.E.T.). G.B. is the holder of the Canada research chair on emerging viruses and antiviral resistance. M.E.T. is the holder of the Tier II Canada Research Chair in Neurobiology of Aging and Cognition. M.B. was a recipient of a doctoral award from Fonds de recherche du Québec - Santé. F.G.I. is a recipient of a full doctoral scholarship from CONACYT, Mexican Council of Science and Technology.

\section{Availability of data and materials}

The data that support the findings of this study are available from the corresponding authors, upon reasonable request.

\section{Declarations}

Ethics approval and consent to participate

All animals were used according to the Canadian Council on Animal Care Guidelines. Experimental procedures were approved by the Animal Care Ethics Committee of Université Laval (protocol no. 2017054).

\section{Consent for publication}

Not applicable.

Competing interests

The authors declare no competing interests. 


\section{Author details}

${ }^{1}$ Centre de Recherche en Infectiologie, Centre de Recherche du CHU de Québec-Université Laval, Quebec City, QC, Canada. ${ }^{2}$ Integrated Program in Neuroscience, McGill University, Montreal, QC, Canada. ${ }^{3}$ Neurosciences Axis, Centre de recherche du CHU de Québec-Université Laval, Quebec City, QC, Canada. ${ }^{4}$ Department of Molecular Medicine, Université Laval, Quebec City, QC, Canada. ${ }^{5}$ Division of Medical Sciences, University of Victoria, Victoria, BC, Canada. ${ }^{6}$ Department of Neurology and Neurosurgery, McGill University, Montreal, QC, Canada. ${ }^{7}$ Department of Biochemistry and Molecular Biology, The University of British Columbia, Vancouver, BC, Canada.

Received: 13 April 2021 Accepted: 16 July 2021

Published online: 16 August 2021

\section{References}

1. Mlakar J, Korva M, Tul N, Popovic M, Poljsak-Prijatelj M, Mraz J, et al. Zika virus associated with microcephaly. N Engl J Med. 2016;374:951-8.

2. Rasmussen SA, Jamieson DJ, Honein MA, Petersen LR. Zika virus and birth defects-reviewing the evidence for causality. N Engl J Med. 2016;374:1981-7.

3. Panchaud A, Stojanov M, Ammerdorffer A, Vouga M, Baud D. Emerging role of Zika virus in adverse fetal and neonatal outcomes. Clin Microbiol Rev. 2016:29:659-94.

4. da Silva IRF, Frontera JA. Bispo de Filippis AM, Nascimento O, Rio-Gbs-Zikv Research Group: Neurologic complications associated with the Zika virus in Brazilian adults. JAMA Neurol. 2017;74:1190-8.

5. Mehta R, Soares CN, Medialdea-Carrera R, Ellul M, da Silva MTT, RosalaHallas A, et al. The spectrum of neurological disease associated with Zika and chikungunya viruses in adults in Rio de Janeiro, Brazil: a case series. PLoS Negl Trop Dis. 2018;12:e0006212.

6. Anaya JM, Rodriguez Y, Monsalve DM, Vega D, Ojeda E, Gonzalez-Bravo $D$, et al. A comprehensive analysis and immunobiology of autoimmune neurological syndromes during the Zika virus outbreak in Cucuta. Colombia J Autoimmun. 2017;77:123-38.

7. Munoz LS, Parra B, Pardo CA. on behalf of the Neuroviruses Emerging in the Americas Study: Neurological implications of Zika virus infection in adults. J Infect Dis. 2017;216:S897-905.

8. Figueiredo CP, Barros-Aragao FGQ, Neris RLS, Frost PS, Soares C, Souza INO, et al. Zika virus replicates in adult human brain tissue and impairs synapses and memory in mice. Nat Commun. 2019;10:3890.

9. Aid M, Abbink P, Larocca RA, Boyd M, Nityanandam R, Nanayakkara O, et al: Zika virus persistence in the central nervous system and lymph nodes of rhesus monkeys. Cell. 2017,169:610-20 e14.

10. Roze B, Najioullah F, Signate A, Apetse K, Brouste Y, Gourgoudou S, et al: Zika virus detection in cerebrospinal fluid from two patients with encephalopathy, Martinique, February 2016. Euro Surveill. 2016,21.

11. Brito Ferreira ML, Antunes de Brito CA, Moreira AJP, de Morais Machado MI, Henriques-Souza A, Cordeiro MT, et al: Guillain-Barre syndrome, acute disseminated encephalomyelitis and encephalitis associated with Zika virus infection in Brazil: detection of viral RNA and isolation of virus during late infection. Am J Trop Med Hyg. 2017,97:1405-9.

12. Carteaux G, Maquart M, Bedet A, Contou D, Brugieres P, Fourati S, et al. Zika virus associated with meningoencephalitis. N Engl J Med. 2016;374:1595-6.

13. Soares CN, Brasil P, Carrera RM, Sequeira P, de Filippis AB, Borges VA, et al. Fatal encephalitis associated with Zika virus infection in an adult. J Clin Virol. 2016;83:63-5.

14. Hygino da Cruz LC, Jr., Nascimento OJM, Lopes F, da Silva IRF: Neuroimaging findings of Zika virus-associated neurologic complications in adults. AJNR Am J Neuroradiol. 2018,39:1967-74.

15. Grant A, Ponia SS, Tripathi S, Balasubramaniam V, Miorin L, Sourisseau M, et al. Zika virus targets human STAT2 to inhibit type I interferon signaling. Cell Host Microbe. 2016;19:882-90.

16. Smith DR, Hollidge B, Daye S, Zeng X, Blancett C, Kuszpit $K$, et al: Neuropathogenesis of Zika virus in a highly susceptible immunocompetent mouse model after antibody blockade of type I interferon. PLoS Negl Trop Dis. 2017,11:e0005296.

17. Dowall SD, Graham VA, Rayner E, Atkinson B, Hall G, Watson RJ, et al: A susceptible mouse model for Zika virus infection. PLoS Negl Trop Dis. 2016,10:e0004658.
18. Aliota MT, Caine EA, Walker EC, Larkin KE, Camacho E, Osorio JE: Characterization of lethal Zika virus infection in AG129 mice. PLoS Negl Trop Dis. 2016,10:e0004682.

19. Lazear HM, Govero J, Smith AM, Platt DJ, Fernandez E, Miner JJ, et al. A mouse model of Zika virus pathogenesis. Cell Host Microbe. 2016;19:720-30.

20. Hayashida E, Ling ZL, Ashhurst TM, Viengkhou B, Jung SR, Songkhunawej $P$, et al. Zika virus encephalitis in immunocompetent mice is dominated by innate immune cells and does not require T or B cells. J Neuroinflammation. 2019;16:177.

21. Piret J, Carbonneau J, Rheaume C, Baz M, Boivin G. Predominant role of IPS-1 over TRIF adaptor proteins in early innate immune response against Zika virus in mice. J Gen Virol. 2018;99:209-18.

22. Li Q, Barres BA. Microglia and macrophages in brain homeostasis and disease. Nat Rev Immunol. 2018;18:225-42.

23. Sierra A, Beccari S, Diaz-Aparicio I, Encinas JM, Comeau S, Tremblay ME: Surveillance, phagocytosis, and inflammation: how never-resting microglia influence adult hippocampal neurogenesis. Neural Plast. 2014,2014:610343.

24. Tremblay ME, Lowery RL, Majewska AK: Microglial interactions with synapses are modulated by visual experience. PLoS Biol. 2010,8:e1000527.

25. Nimmerjahn A, Kirchhoff F, Helmchen F. Resting microglial cells are highly dynamic surveillants of brain parenchyma in vivo. Science. 2005;308:1314-8.

26. Wake H, Moorhouse AJ, Jinno S, Kohsaka S, Nabekura J. Resting microglia directly monitor the functional state of synapses in vivo and determine the fate of ischemic terminals. J Neurosci. 2009;29:3974-80.

27. Rock RB, Gekker G, Hu S, Sheng WS, Cheeran M, Lokensgard JR, et al. Role of microglia in central nervous system infections. Clin Microbiol Rev. 2004;17:942-64.

28. Chen Z, Zhong D, Li G. The role of microglia in viral encephalitis: a review. J Neuroinflammation. 2019;16:76.

29. Davalos D, Grutzendler J, Yang G, Kim JV, Zuo Y, Jung S, et al. ATP mediates rapid microglial response to local brain injury in vivo. Nat Neurosci. 2005:8:752-8.

30. Winkler CW, Myers LM, Woods TA, Messer RJ, Carmody AB, McNally $\mathrm{KL}$, et al. Adaptive immune responses to zika virus are important for controlling virus infection and preventing infection in brain and testes. J Immunol. 2017;198:3526-35.

31. Shao Q, Herrlinger S, Yang SL, Lai F, Moore JM, Brindley MA, et al. Zika virus infection disrupts neurovascular development and results in postnatal microcephaly with brain damage. Development. 2016;143:4127-36

32. Elmore MR, Najafi AR, Koike MA, Dagher NN, Spangenberg EE, Rice RA, et al. Colony-stimulating factor 1 receptor signaling is necessary for microglia viability, unmasking a microglia progenitor cell in the adult brain. Neuron. 2014;82:380-97.

33. Dagher NN, Najafi AR, Kayala KM, Elmore MR, White TE, Medeiros R, et al. Colony-stimulating factor 1 receptor inhibition prevents microglial plaque association and improves cognition in 3xTg-AD mice. J Neuroinflammation. 2015;12:139.

34. Lanciotti RS, Lambert AJ, Holodniy M, Saavedra S, Signor Ldel C. Phylogeny of Zika virus in Western hemisphere, 2015. Emerg Infect Dis. 2016;22:933-5.

35. Enlow W, Piret J, Boivin G: Droplet digital PCR and immunohistochemistry techniques to detect Zika virus in the central nervous system of mice. In Zika virus: Methods and protocols. Edited by Kobinger GP, Racine T. New York: Springer; 2020: 41-57: Methods in molecular biology].

36. Paxinos G, Franklin KB. Paxinos and Franklin's the mouse brain in stereotaxic coordinates. 4th ed. Amsterdam: Elsevier/Academic Press; 2013.

37. Gonzalez Ibanez F, Picard K, Bordelau M, Sharma K, Bisht K, Tremblay ME: Immunofluorescence staining using IBA1 and TMEM119 for microglial density, morphology and peripheral myeloid cell infiltration analysis in mouse brain. J Vis Exp. 2019.

38. Tremblay ME, Zettel ML, Ison JR, Allen PD, Majewska AK. Effects of aging and sensory loss on glial cells in mouse visual and auditory cortices. Glia. 2012;60:541-58.

39. Bordeleau M, Lacabanne C, Fernandez de Cossio L, Vernoux N, Savage JC, Gonzalez-Ibanez F, et al: Microglial and peripheral immune priming is partially sexually dimorphic in adolescent mouse offspring exposed to maternal high-fat diet. J Neuroinflammation. 2020,17:264. 
40. Tremblay ME, Riad M, Majewska A: Preparation of mouse brain tissue for immunoelectron microscopy. J Vis Exp. 2010;41:e2021.

41. Peters A, Palay SL, Webster H: The fine structure of the nervous sytem. Neurons and their supporting cells. J Neuropathol Exp Neurol. 1991:282-.

42. St-Pierre MK, Bordeleau M, Tremblay ME. Visualizing dark microglia. Methods Mol Biol. 2019;2034:97-110.

43. De Duve C. The lysosome. Sci Am. 1963;208:64-72.

44. Holtzman E, Novikoff AB, Villaverde H. Lysosomes and GERL in normal and chromatolytic neurons of the rat ganglion nodosum. J Cell Biol. 1967;33:419-35

45. Nandy K. Properties of neuronal lipofuscin pigment in mice. Acta Neuropathol. 1971;19:25-32.

46. El Hajj H, Savage JC, Bisht K, Parent M, Vallieres L, Rivest S, et al. Ultrastructural evidence of microglial heterogeneity in Alzheimer's disease amyloid pathology. J Neuroinflammation. 2019;16:87.

47. Chavez-Valdez R, Flock DL, Martin LJ, Northington FJ. Endoplasmic reticulum pathology and stress response in neurons precede programmed necrosis after neonatal hypoxia-ischemia. Int J Dev Neurosci. 2016;48:58-70.

48. Long Q, Zhao D, Fan W, Yang L, Zhou Y, Qi J, et al. Modeling of mitochondrial donut formation. Biophys J. 2015;109:892-9.

49. Maxfield FR, Barbosa-Lorenzi VC, Singh RK. Digestive exophagy: phagocyte digestion of objects too large for phagocytosis. Traffic. 2020;21:6-12.

50. Haka AS, Barbosa-Lorenzi VC, Lee HJ, Falcone DJ, Hudis CA, Dannenberg $\mathrm{AJ}$, et al. Exocytosis of macrophage lysosomes leads to digestion of apoptotic adipocytes and foam cell formation. J Lipid Res. 2016;57:980-92.

51. Fanselow MS, Dong HW. Are the dorsal and ventral hippocampus functionally distinct structures? Neuron. 2010;65:7-19.

52. Li M, Zhang D, Li C, Zheng Z, Fu M, Ni F, et al. Characterization of Zika virus endocytic pathways in human glioblastoma cells. Front Microbiol. 2020:11:242.

53. Rossignol ED, Peters KN, Connor JH, Bullitt E: Zika virus induced cellular remodelling. Cell Microbiol. 2017;19. https://doi.org/10.1111/cmi.12740,

54. Li H, Saucedo-Cuevas L, Regla-Nava JA, Chai G, Sheets N, Tang W, et al. Zika virus infects neural progenitors in the adult mouse brain and alters proliferation. Cell Stem Cell. 2016;19:593-8.

55. Garber C, Soung A, Vollmer LL, Kanmogne M, Last A, Brown J, et al. T cells promote microglia-mediated synaptic elimination and cognitive dysfunction during recovery from neuropathogenic flaviviruses. Nat Neurosci. 2019;22:1276-88.

56. Buttner C, Heer M, Traichel J, Schwemmle M, Heimrich B. Zika virus-mediated death of hippocampal neurons is independent from maturation state. Front Cell Neurosci. 2019;13:389.

57. Vasek MJ, Garber C, Dorsey D, Durrant DM, Bollman B, Soung A, et al. A complement-microglial axis drives synapse loss during virus-induced memory impairment. Nature. 2016;534:538-43.

58. Chauhan PS, Khanna VK, Kalita J, Misra UK. Japanese encephalitis virus infection results in transient dysfunction of memory learning and cholinesterase inhibition. Mol Neurobiol. 2017;54:4705-15.

59. Zucker J, Neu N, Chiriboga CA, Hinton VJ, Leonardo M, Sheikh A, et al. Zika virus-associated cognitive impairment in adolescent, 2016. Emerg Infect Dis. 2017;23:1047-8.

60. Jurado KA, Yockey LJ, Wong PW, Lee S, Huttner AJ, I wasaki A. Antiviral CD8 T cells induce Zika-virus-associated paralysis in mice. Nat Microbiol. 2018:3:141-7.

61. Kim J, Alejandro B, Hetman M, Hattab EM, Joiner J, Schroten H, et al: Zika virus infects pericytes in the choroid plexus and enters the central nervous system through the blood-cerebrospinal fluid barrier. PLoS Pathog. 2020,16:e1008204.

62. Papa MP, Meuren LM, Coelho SVA, Lucas CGO, Mustafa YM, Lemos Matassoli $F$, et al. Zika virus infects, activates, and crosses brain microvascular endothelial cells, without barrier disruption. Front Microbiol. 2017;8:2557.

63. Lum FM, Low DK, Fan Y, Tan JJ, Lee B, Chan JK, et al. Zika virus infects human fetal brain microglia and induces inflammation. Clin Infect Dis. 2017;64:914-20.

64. Wang J, Liu J, Zhou R, Ding X, Zhang Q, Zhang C, et al. Zika virus infected primary microglia impairs NPCs proliferation and differentiation. Biochem Biophys Res Commun. 2018;497:619-25.

65. Mesci P, Macia A, LaRock CN, Tejwani L, Fernandes IR, Suarez NA, et al. Modeling neuro-immune interactions during Zika virus infection. Hum Mol Genet. 2018;27:41-52.
66. Diop F, Vial T, Ferraris P, Wichit S, Bengue M, Hamel R, et al: Zika virus infection modulates the metabolomic profile of microglial cells. PLoS One. 2018,13:e0206093.

67. Olmo IG, Carvalho TG, Costa W, Alves-Silva J, Ferrari CZ, Izidoro-Toledo TC, et al. Zika virus promotes neuronal cell death in a non-cell autonomous manner by triggering the release of neurotoxic factors. Front Immunol. 2017:8:1016.

68. Cle M, Desmetz C, Barthelemy J, Martin MF, Constant O, Maarifi G, et al: Zika virus infection promotes local inflammation, cell adhesion molecule upregulation, and leukocyte recruitment at the blood-brain barrier. mBio. 2020;11:e01183-20.

69. Selenica ML, Alvarez JA, Nash KR, Lee DC, Cao C, Lin X, et al. Diverse activation of microglia by chemokine (C-C motif) ligand 2 overexpression in brain. J Neuroinflammation. 2013;10:86.

70. Bai F, Kong KF, Dai J, Qian F, Zhang L, Brown CR, et al. A paradoxical role for neutrophils in the pathogenesis of West Nile virus. J Infect Dis. 2010;202:1804-12.

71. Trinchieri G. Interleukin-12: a proinflammatory cytokine with immunoregulatory functions that bridge innate resistance and antigen-specific adaptive immunity. Annu Rev Immunol. 1995;13:251-76.

72. Tsuda M, Masuda T, Kitano J, Shimoyama H, Tozaki-Saitoh H, Inoue K. IFNgamma receptor signaling mediates spinal microglia activation driving neuropathic pain. Proc Natl Acad Sci U S A. 2009;106:8032-7.

73. Villeda SA, Luo J, Mosher KI, Zou B, Britschgi M, Bieri G, et al. The ageing systemic milieu negatively regulates neurogenesis and cognitive function. Nature. 2011;477:90-4.

74. Luo XG, Chen SD. The changing phenotype of microglia from homeostasis to disease. Transl Neurodegener. 2012;1:9.

75. Savage JC, Carrier M, Tremblay ME. Morphology of microglia across contexts of health and disease. Methods Mol Biol. 2019;2034:13-26.

76. van Horssen J, Singh S, van der Pol S, Kipp M, Lim JL, Peferoen L, et al. Clusters of activated microglia in normal-appearing white matter show signs of innate immune activation. J Neuroinflammation. 2012;9:156.

77. Troscher AR, Wimmer I, Quemada-Garrido L, Kock U, GessI D, Verberk SGS, et al. Microglial nodules provide the environment for pathogenic $T$ cells in human encephalitis. Acta Neuropathol. 2019;137:619-35.

78. Tay TL, Mai D, Dautzenberg J, Fernandez-Klett F, Lin G, Sagar, et al: A new fate mapping system reveals context-dependent random or clonal expansion of microglia. Nat Neurosci. 2017,20:793-803.

79. Fontainhas AM, Wang M, Liang KJ, Chen S, Mettu P, Damani M, et al: Microglial morphology and dynamic behavior is regulated by ionotropic glutamatergic and GABAergic neurotransmission. PLoS One. 2011;6:e15973

80. Milior G, Lecours C, Samson L, Bisht K, Poggini S, Pagani F, et al. Fractalkine receptor deficiency impairs microglial and neuronal responsiveness to chronic stress. Brain Behav Immun. 2016;55:114-25.

81. Hellwig S, Brioschi S, Dieni S, Frings L, Masuch A, BlankT, et al. Altered microglia morphology and higher resilience to stress-induced depression-like behavior in CX3CR1-deficient mice. Brain Behav Immun. 2016;55:126-37.

82. Yamasaki R, Lu H, Butovsky O, Ohno N, Rietsch AM, Cialic R, et al. Differential roles of microglia and monocytes in the inflamed central nervous system. J Exp Med. 2014;211:1533-49.

83. Wang $X$, Zhao L, Zhang J, Fariss RN, Ma W, Kretschmer F, et al. Requirement for microglia for the maintenance of synaptic function and integrity in the mature retina. J Neurosci. 2016;36:2827-42.

84. Tremblay ME, Zhang I, Bisht K, Savage JC, Lecours C, Parent M, et al. Remodeling of lipid bodies by docosahexaenoic acid in activated microglial cells. J Neuroinflammation. 2016;13:116.

85. Lively S, Schlichter LC. The microglial activation state regulates migration and roles of matrix-dissolving enzymes for invasion. J Neuroinflammation. 2013;10:75.

86. Seitz S, Clarke P, Tyler KL. Pharmacologic depletion of microglia increases viral load in the brain and enhances mortality in murine models of Flavivirus-induced encephalitis. J Virol. 2018;92:e00525-18.

87. Chhatbar C, Detje CN, Grabski E, Borst K, Spanier J, Ghita L, et al:Type I interferon receptor signaling of neurons and astrocytes regulates microglia activation during viral encephalitis. Cell Rep. 2018,25:118-29 e4.

88. Wheeler DL, Sariol A, Meyerholz DK, Perlman S. Microglia are required for protection against lethal coronavirus encephalitis in mice. J Clin Invest. 2018;128:931-43. 
89. Fekete R, Cserep C, Lenart N, Toth K, Orsolits B, Martinecz B, et al. Microglia control the spread of neurotropic virus infection via P2Y12 signalling and recruit monocytes through P2Y12-independent mechanisms. Acta Neuropathol. 2018;136:461-82.

90. Funk KE, Klein RS. CSF1R antagonism limits local restimulation of antiviral CD8(+) T cells during viral encephalitis. J Neuroinflammation. 2019;16:22.

91. Morizawa YM, Hirayama Y, Ohno N, Shibata S, Shigetomi E, Sui Y, et al. Reactive astrocytes function as phagocytes after brain ischemia via ABCA1-mediated pathway. Nat Commun. 2017:8:28.

92. Kwon HS, Koh SH. Neuroinflammation in neurodegenerative disorders: the roles of microglia and astrocytes. Transl Neurodegener. 2020;9:42.

93. Damisah EC, Hill RA, Rai A, Chen F, Rothlin CV, Ghosh S, et al: Astrocytes and microglia play orchestrated roles and respect phagocytic territories during neuronal corpse removal in vivo. Sci Adv. 2020,6:eaba3239.

94. Konishi H, Okamoto T, Hara Y, Komine O, Tamada H, Maeda M, et al: Astrocytic phagocytosis is a compensatory mechanism for microglial dysfunction. EMBO J. 2020;39:e104464.

95. Shinozaki Y, Shibata K, Yoshida K, Shigetomi E, Gachet C, Ikenaka K, et al. Transformation of astrocytes to a neuroprotective phenotype by microglia via P2Y1 receptor downregulation. Cell Rep. 2017;19:1151-64.
96. Dowall SD, Graham VA, Rayner E, Hunter L, Atkinson B, Pearson G, et al: Lineage-dependent differences in the disease progression of Zika virus infection in type-l interferon receptor knockout (A129) mice. PLoS Negl Trop Dis. 2017;11:e0005704

97. Lenz KM, McCarthy MM. A starring role for microglia in brain sex differences. Neuroscientist. 2015;21:306-21.

98. Lenz KM, Nugent BM, Haliyur R, McCarthy MM. Microglia are essential to masculinization of brain and behavior. J Neurosci. 2013;33:2761-72.

99. Ghosh S, Klein RS. Sex drives dimorphic immune responses to viral infections. J Immunol. 2017;198:1782-90.

\section{Publisher's Note}

Springer Nature remains neutral with regard to jurisdictional claims in published maps and institutional affiliations.
Ready to submit your research? Choose BMC and benefit from:

- fast, convenient online submission

- thorough peer review by experienced researchers in your field

- rapid publication on acceptance

- support for research data, including large and complex data types

- gold Open Access which fosters wider collaboration and increased citations

- maximum visibility for your research: over $100 \mathrm{M}$ website views per year

At BMC, research is always in progress.

Learn more biomedcentral.com/submissions 